\title{
Discovery of $3,3^{\prime}$-diindolylmethanes as potent antileishmanial agents
}

\author{
Sandip B. Bharate ${ }^{a,}{ }^{*}$, Jaideep B. Bharate ${ }^{a}$, Shabana I. Khan ${ }^{b}$, Babu L. Tekwani ${ }^{b}$, Melissa R. \\ Jacob $^{b}$, Ramesh Mudududdla ${ }^{a}$, Rammohan R. Yadava, Baljinder Singh ${ }^{c}$, P. R. Sharma ${ }^{d}$, \\ Sudip Maity ${ }^{e}$, Baldev Singh ${ }^{\star}, \mathrm{c}$, Ikhlas A. Khan ${ }^{\mathrm{b}}$, and Ram A. Vishwakarma ${ }^{\mathrm{a}, \mathrm{c},{ }^{*}}$ \\ aMedicinal Chemistry Division, Indian Institute of Integrative Medicine (CSIR), Canal Road, \\ Jammu-180001, India \\ bNational Centre for Natural Products Research (NCNPR), School of Pharmacy, University of \\ Mississippi, MS 38677, USA \\ 'Natural Products Chemistry Division, Indian Institute of Integrative Medicine (CSIR), Canal \\ Road, Jammu-180001, India \\ dPharmacology Division, Indian Institute of Integrative Medicine (CSIR), Canal Road, \\ Jammu-180001, India \\ ${ }^{e}$ Central Institute of Mining and Fuel Research (CIMFR), Dhanbad, Jharkhand-826001, India
}

\section{Abstract}

An efficient protocol for synthesis of 3,3'-diindolyl methanes using recyclable Fe - pillared interlayered clay (Fe-PILC) catalyst under aqueous medium have been developed. All synthesized 3,3'-diindolylmethanes showed promising antileishmanial activity against Leishmania donovani promastigotes as well as axenic amastigotes. Structure-activity relationship analysis revealed that nitroaryl substituted diindolylmethanes showed potent antileishmanial activity. The 4-nitrophenyl linked 3,3'-diindolylmethane $\mathbf{8 g}$ was found to be the most potent antileishmanial analog showing $\mathrm{IC}_{50}$ values of 7.88 and $8.37 \mu \mathrm{M}$ against both $L$. donovani promastigotes and amastigotes, respectively. Further, a pharmacophore based QSAR model was established to understand the crucial molecular features of 3,3'-diindolylmethanes essential for potent antileishmanial activity. These compounds also exhibited promising antifungal activity against Cryptococcus neoformans, wherein fluorophenyl substituted 3,3' -diindolylmethanes were found to be most potent antifungal agents. Developed synthetic protocol will be useful for economical and eco-friendly synthesis of potent antileishmanial and antifungal 3,3' -diindolylmethane class of compounds.

\footnotetext{
(c) 2013 Elsevier Masson SAS. All rights reserved.

*Authors for correspondence Medicinal Chemistry Division, Indian Institute of Integrative Medicine (CSIR), Canal Road, Jammu-180001, India sbharate@iiim.ac.in (SBB); ram@iiim.ac.in (RAV); baldevsingh@iiim.ac.in (BS) Fax: +91-191-2569333; Tel: +91-191-2569111

Supplementary material Experimental details of catalyst preparation and its characterization and pharmacophore modelling; and NMR data scans of representative compounds are provided.

Publisher's Disclaimer: This is a PDF file of an unedited manuscript that has been accepted for publication. As a service to our customers we are providing this early version of the manuscript. The manuscript will undergo copyediting, typesetting, and review of the resulting proof before it is published in its final citable form. Please note that during the production process errors may be discovered which could affect the content, and all legal disclaimers that apply to the journal pertain.
} 


\section{Keywords}

3,3'-Diindolylmethanes; Antileishmanial; Antimalarial; Leishmania donovani; Antifungal; Fepillared interlayered clay

\section{Introduction}

Parasitic diseases such as malaria, leishmaniasis, trypanosomiasis affect millions of people worldwide and pose a major health problem in developing countries [1, 2]. Amongst these malaria and leishmaniasis have affected major population with increasing number of new cases each year. Leishmaniasis is caused by protozoan parasites that belong to the genus Leishmania and is transmitted by the bite of certain species of sand fly (subfamily Phlebotominae). Most of the current drugs used to treat parasitic diseases are decades old and have many limitations, including the emergence of drug resistance. For leishmaniasis, either the first-line pentavalent antimonials or second-line drugs such as amphotericin B are available, which are costly and have serious side-effects, and are getting resistant to pathogens after treatment for several weeks, and hence there is a need for new antileshmanial agents with improved efficacy and less side-effects for both visceral and cutaneous leishmaniasis $[3,4]$.

Bisindole class of compounds are known to possess diverse range of pharmacological activities such as anticancer [5-7], antimicrobial [8-11] etc. Hamacanthin A (1), a bisindole alkaloid isolated from the sponge Hamacantha sp [11] and Spongosorites sp [8] showed potent antibacterial activity against $S$. aureus and MRS with MIC of $6.45 \mu \mathrm{M}$ and antifungal activity against $B$. subtillis with MIC of $3.22 \mu \mathrm{M}$ [8]. Furthermore, bisindoles have also been reported as fluorescent molecular probes [12] of biological interest. Amongst various antileishmanial scaffolds reported, indole alkaloids [13-18] such as 2-3 [18] showed promising activity against Leishmania parasite. Munoz et al [18] observed that dimeric indole alkaloids showed better antibacterial and antileishmanial activities compared to monomeric indole alkaloids. Dimeric alkaloids conodurine $\mathbf{2}$ and $\mathrm{N}$-demethylconodurine $\mathbf{3}$ showed strong activity against the intracellular amastigote form of Leishmania. Furthermore, 3,3'-diindolylmethane (DIM, 4) is a cancer chemopreventive agent present in cruciferous vegetables such as broccoli, brussels sprouts, cabbage and kale [5]. Structures of bisindole alkaloids 1-4 are shown in Figure 1.

Due to promising pharmacological activities $[7,19,20]$ of bisindoles or diindolylmethanes, plenty of synthetic methods are available in literature for their synthesis; however most of these methods involves treatment of indoles with aldehydes in presence of homogeneous acid catalysts or lewis acids [21-24] and only few reports on the use of heterogeneous catalysts such as inorganic-supported polyoxometalates [25], polyaniline-bismoclite composite [26] and zeolites [27, 28]. Despite these reports, development of a hazard-free, waste-free, and energy-efficient synthetic protocol will be of great use for economical synthesis of this class of compounds. In continuation to our efforts towards development of efficient synthetic methodologies for preparation of biologically important scaffolds [29-31], and our efforts in the area of indole chemistry [32-35], herein we have developed an efficient protocol (Figure 2) for preparation of potent antileishmanial 3,3' diindolylmethanes. 


\section{Results and discussion}

\subsection{Synthesis of 3,3'-diindolyl methanes}

Keeping in mind earlier findings that requirement of acidity is essential for the preparation of 3,3'-diindolylmethanes, we explored Fe-PILC catalysts $\mathbf{A}$ and $\mathbf{B}$ varying in their surface acidity. Reaction between $1 \mathrm{H}$-indole (5a) and 4-hydroxy benzaldehyde (6a) was used as a model reaction (Table 1). Solvent optimization studies revealed that methylene chloride and water were best solvents producing higher yields. Catalyst loading as low as $15 \mathrm{~mol} \%$ was found to be efficient producing excellent yields of products. Further, catalyst $\mathbf{B}$ was found to be better as compared to catalyst $\mathbf{A}$. Thus catalyst $\mathbf{B}$ and water as reaction medium at room temperature were chosen for further scope exploration studies. Furthermore, we compared the reactivity of Fe-PILC B with plane Montmorillonite clay K10 (entries 9 and 10). Product 7a was not formed using clay K10 after 6 h of reaction time (entry 9), however $\sim 30 \%$ product was formed when reaction was continued for $16 \mathrm{~h}$ (entry 10). These results clearly indicate the significant enhancement of catalytic activity of clay after pillaring it with iron.

Next, we studied scope of the reaction for various substituted indoles and different aldehydes. Treatment of indole (5a) with various substituted aryl and heteroaryl aldehydes in water in presence of $15 \mathrm{~mol} \%$ of Fe-PILC B produced corresponding 3,3' diindolylmethanes 7a-7o in excellent yields as shown in Figure 3. Indoles substituted with electron withdrawing group (e.g. Iodo, Figure 4) as well as electron donating group (e.g. OMe, Figure 5) on treatment with various aryl and heteroaryl aldehydes produced corresponding 3,3' -diindolylmethanes in excellent yields as shown in Figure 4 and 5. Similarly aldehydes with both electron donating as well as electron withdrawing groups participated well in this reaction. Recyclability of the Fe-PILC B catalyst was checked to prove the heterogeneous nature and its repeated use. Treatment of $1 H$-indole (5a) and 4hydroxy benzaldehyde (6a) in water in presence of $15 \mathrm{~mol} \%$ Fe-PILC B led to formation of $3,3^{\prime}$-diindolylmethane $\mathbf{7 a}$ in $85,82,78,68 \%$ yield over four cycles respectively.

In order to understand the efficiency and catalytic activity as a function of catalyst composition, physical nature and surface acidity, the Fe-PILC B catalyst was characterized for specific surface area, temperature programmed reduction (TPR), temperature programmed desorption (TPD) and scanning electron microscopy (SEM) analysis. Surface area results evidenced that catalyst $\mathbf{B}$ is composed of fine aggregates, which was also supported by SEM analysis. Surface area for natural montmorillonite clay K10 and Fe-PILC $\mathbf{B}$ was found to be $52 \mathrm{~m}^{2} \mathrm{~g}^{-1}$ and $102 \mathrm{~m}^{2} \mathrm{~g}^{-1}$, indicating increase in the surface area in Fepillared clays. SEM analysis of Fe-PILC B showed that metal is randomly distributed over the support surface with flake formation, which was also supported by dispersion analysis (upto 99.4\%). The average crystallite size of the metal was $11.60 \mathrm{~A}^{\mathrm{o}}$. Further, SEM analysis also showed that Fe particles were present in the form of aggregates and not as a continuous film. Highly dispersed metal on the support is able to adsorb substrate and /or reagent to the high extent. TPD analysis showed that the Fe-PILC B contained enormously high surface acidity compared to the original clay montmorillonite K10. Total acidity of the catalyst was found to be $7.91 \mathrm{mmol} \mathrm{NH}_{3} / \mathrm{g}$ catalyst, which was distributed on the surface of the clay support as $47 \%$ (3.75 $\mathrm{mmol} \mathrm{NH}_{3} / \mathrm{g}$ catalyst), $18 \%$ (1.40 $\mathrm{mmol} \mathrm{NH}_{3} / \mathrm{g}$ catalyst) and $35 \%$ ( $2.76 \mathrm{mmol} \mathrm{NH}_{3} / \mathrm{g}$ catalyst) of weak, medium and strong acidic sites. Further, a $\mathrm{H}_{2}{ }^{-}$ temperature-programmed reduction (TPR) profile of the Fe-PILC B indicated that iron oxides gets reduced to $\mathrm{Fe}$ in three steps. Initially $\mathrm{Fe}_{2} \mathrm{O}_{3}$ gets reduced to $\mathrm{Fe}_{3} \mathrm{O}_{4}$ at $415^{\circ} \mathrm{C}$, which further gets reduced to $\mathrm{FeO}$ and then consequently to $\mathrm{Fe}$ at $470{ }^{\circ} \mathrm{C}$ (Figure $\mathrm{S} 1$ of supplementary information). 


\subsection{Biological evaluation}

All synthesized 3,3' -diindolylmethanes were evaluated for antileishmanial, antimalarial, antibacterial and antifungal, activities. The in vitro antileishmanial activity of 3,3'diindolylmethanes was tested against a culture of both $L$. donovani promastigotes and axenic amastigotes. Several compounds showed promising antileishmanial activity as depicted in Table 2. Amongst all tested analogs, 5-nitrofuryl substituted 5,5' -diiodo 3,3'diindolylmethane $\mathbf{8 j}$ was found to be most promising compound against $L$. donovani promastigotes showing $\mathrm{IC}_{50}$ and $\mathrm{IC}_{90}$ values of 3.02 and $6.22 \mu \mathrm{M}$ which was comparable to control drug pentamidine. However, the 4-nitrophenyl substituted 5,5' -diiodo 3,3' diindolylmethane $\mathbf{8 g}$ showed potent activity against both promastigotes as well as amastigotes with $\mathrm{IC}_{50}$ values of 7.88 and $8.37 \mu \mathrm{M}$, respectively. Analysis of structureactivity relationship revealed that $3,3^{\prime}$-diindolylmethanes substituted with nitro-substituted aromatic (e.g. 7l, 8g, 9g) or heteroaromatic moiety (e.g. 7o, 8j) showed potent antileishmanial activity against $L$. donovani promastigotes and amastigotes.

All compounds were also evaluated for in vitro antimalarial activity against chloroquinesensitive (D6) and resistant (W2) clones of Plasmodium falciparum via determination of plasmodial LDH activity [36]. 2,6-Dichlorophenyl linked 3,3'-diindolylmethane $\mathbf{7 j}$ showed antimalarial activity against D6 clone of Plasmodium falciparum with $\mathrm{IC}_{50}$ value of 12.1 $\mu \mathrm{M}$. None of the $3,3^{\prime}$-diindolylmethane showed cytotoxicity towards mammalian kidney fibroblasts (vero) cells at concentration upto $4.6 \mu \mathrm{g} / \mathrm{mL}$.

The antibacterial activity was tested against Staphylococcus aureus, methicillin-resistant Staphylococcus aureus, Mycobacterium intracellulare, Escherichia coli and Pseudomonas aeruginosa. Susceptibility of these microorganisms (except $M$. intracellulare) to test compounds was determined according to a modified version of CLSI methods [37-39]. Susceptibility of $M$. intracellulare was done using the modified Alamar Blue procedure [40]. Ciprofloxacin was used as positive control for comparison. Results of antibacterial activity are shown in Table 3 . All tested diindolylmethanes were active only against $S$. aureus and methicilin-resistant $S$. aureus. Amongst tested compounds, hydroxyphenyl substituted 5,5'diiodo-diindolylmethanes $\mathbf{8 a}$ and $\mathbf{8 b}$ showed most potent antibacterial activity against $S$. aureus and MRS with MIC values in the range of 2.0 to $4.3 \mu \mathrm{M}$. 3,5-Difluorophenyl substituted 3,3' -diindolylmethane $7 \mathbf{k}$ also showed potent antibacterial activity against $S$. aureus and MRS with MIC values of 3.49 and $6.98 \mu \mathrm{M}$ respectively. Only two 3,3'diindolylmethanes $7 \mathbf{o}$ and $\mathbf{9 c}$ showed activity against $M$. intracellulare with $\mathrm{IC}_{50}$ values of 52.9 and $39.6 \mu \mathrm{M}$ respectively.

Antifungal activities were evaluated against a panel of pathogenic fungi (Candida albicans, Cryptococcus neoformans, Aspergillus fumigatus) associated with opportunistic infections. Amphoterecin B was used as positive control for comparison. Several compounds showed promising activity against $C$. neoformans, however no activity was found against other fungi. Fluorophenyl substituted 3,3'-diindolylmethanes $\mathbf{7 g}$ and $\mathbf{7 k}$ showed potent antifungal activity against $C$. neoformans with MIC values of 2.99 and $3.49 \mu \mathrm{M}$ respectively. Hydroxyphenyl substituted 5,5' -diiodo-diindolylmethanes $\mathbf{8 a}$ which showed potent antibacterial activity, also exhibited promising antifungal activity against $C$. neoformans with MIC of $4.24 \mu \mathrm{M}$. Antifungal activity of 3,3'-diindolylmethanes against $C$. neoformans is shown in Table 4.

\subsection{Pharmacophore model for antileishmanial 3,3'-diindolylmethanes}

A pharmacophore based QSAR model [41, 42] was established for antileishmanial 3,3'diindolylmethanes in order to understand the key molecular features essential for antileishmanial activity against $L$. donovani promastigotes. As depicted in Figure 6, the 
selected pharmacophore model comprises two H-bond donors and four aromatic ring features. Developed model showed excellent statistical parameters, thus guaranties its utility to design new promising antileishmanial $3,3^{\prime}$-diindolylmethanes.

\section{Conclusion}

In summary, we have developed simple and efficient green protocol for preparation of structurally diverse $3,3^{\prime}$-diindolylmethanes. Nitroaryl substituted $3,3^{\prime}$-diindolylmethanes were potent antileishmanial agents possessing activity comparable to pentamidine. 3,3'Diindolylmethanes also showed promising antibacterial and antifungal activities.

Fluorophenyl substituted 3,3'-diindolylmethanes were found to be most potent antifungal compounds against $C$. neoformans. Thus, herein we have shown that developed synthetic protocol is highly efficient for economical synthesis of potent antifungal and antileishmanial diindolylmethanes. Furthermore, a developed statistically significant pharmacophore model can be used for designing potent antileishmanial 3,3'-diindolylmethanes.

\section{Experimental Section}

\subsection{General}

All chemicals were obtained from Sigma-Aldrich Company and used as received. ${ }^{1} \mathrm{H},{ }^{13} \mathrm{C}$ and DEPT NMR spectra were recorded on Brucker-Avance DPX FT-NMR 500 and 400 $\mathrm{MHz}$ instruments. Chemical data for protons are reported in parts per million (ppm) downfield from tetramethylsilane and are referenced to the residual proton in the NMR solvent $\left(\mathrm{CDCl}_{3}, 7.26 \mathrm{ppm}\right)$. Carbon nuclear magnetic resonance spectra $\left({ }^{13} \mathrm{C} \mathrm{NMR}\right)$ were recorded at $125 \mathrm{MHz}$ or $100 \mathrm{MHz}$ : chemical data for carbons are reported in parts per million (ppm, $\delta$ scale) downfield from referenced to the carbon resonance of the solvent $\left(\mathrm{CDCl}_{3}, 77 \mathrm{ppm}\right)$. ESI-MS and HRMS spectra were recorded on Agilent 1100 LC-Q-TOF and HRMS-6540-UHD machines. IR spectra were recorded on Perkin-Elmer IR spectrophotometer. Melting points were recorded on digital melting point apparatus.

\subsection{General procedure for synthesis of 3,3'-diindolylmethanes using Fe-PILC B catalyst}

To the solution of indole 5a-c and aldehyde $\mathbf{6}$ in water was added $15 \mathrm{~mol} \% \mathrm{Fe}-\mathrm{PILC}$ B and reaction mixture was stirred at room temperature for 6 to $10 \mathrm{~h}$. Completion of the reaction was monitored by TLC. After completion of reaction, reaction mixture was filtered and filtrate was concentrated on vacuo rotavapor to get crude product. Crude product was purified by silica gel (\#100-200) column chromatography to get 3,3'-diindolylmethanes 7a$\mathbf{k , ~ 8 a - j}$ and 9a-k in 60-78\% yields. Compounds 7a [26, 43], 7b [26-28], 7c [27, 28, 43-45], 7d [46], 7f [47], 7h [22, 25-28, 44, 48], 7j [47], 7k [49], 71 [22, 25, 26, 43-45], 7m [46, 50], 7n [43], 7o [43], 8f [49], 9d [51], 9f [49] and 9g [52] were characterized by comparison of their spectral data with literature values. Spectral data for new compounds is provided below.

4.2.1. 3,3'-(4-Methoxy-3-bromophenyl-methanediyl)-bisindole (7e)—Black solid; m.p. 104-106 ${ }^{\circ} \mathrm{C} ;{ }^{1} \mathrm{H}$ NMR $\left(\mathrm{CDCl}_{3}, 400 \mathrm{MHz}\right): \delta 7.86(\mathrm{~s}, 2 \mathrm{H}), 7.46(\mathrm{~d}, \mathrm{~J}=12 \mathrm{H}, 1 \mathrm{H})$, 7.35-7.30 (m, 4H), 7.16-7.11 (m, 3H), $6.96(\mathrm{t}, J=7.2,2 \mathrm{H}), 6.76(\mathrm{~d}, J=8.4 \mathrm{~Hz}, 1 \mathrm{H}), 6.58(\mathrm{~s}$, $2 \mathrm{H}), 5.74(\mathrm{~s}, 1 \mathrm{H}), 3.73(\mathrm{~s}, 3 \mathrm{H}) ;{ }^{13} \mathrm{C} \mathrm{NMR}\left(\mathrm{CDCl}_{3}, 125 \mathrm{MHz}\right): \delta 154.11,137.92,136.71$, 133.33, 128.44, 126.85, 123.60, 121.90, 119.76, 119.39, 111.84, 111.69, 111.04, 56.28, 38.88; IR $\left(\mathrm{CHCl}_{3}\right): \nu_{\max } 3411,2929,1604,1509,1456,1300,1216 \mathrm{~cm}^{-1}$; ESI-MS: $\mathrm{m} / \mathrm{z} 431$ $[\mathrm{M}+1]^{+}$; HRMS: $\mathrm{m} / \mathrm{z} 429.0595$ calcd for $\mathrm{C}_{24} \mathrm{H}_{19} \mathrm{BrN}_{2} \mathrm{O}-\mathrm{H}^{+}$(429.0597).

\subsubsection{3,3'-(4-Fluoro-3-bromo-phenylmethanediyl)-bisindole (7g)-Maroon} colored solid; m.p. $102-104{ }^{\circ} \mathrm{C} ;{ }^{1} \mathrm{H}$ NMR $\left(\mathrm{CDCl}_{3}, 400 \mathrm{MHz}\right): \delta 7.90$ (s, 2H), 7.50-7.45 (dd, 
$J=2.4,6.8 \mathrm{~Hz}, 1 \mathrm{H}), 7.37(\mathrm{t}, J=7.9 \mathrm{~Hz}, 4 \mathrm{H}), 7.25-7.17(\mathrm{~m}, 3 \mathrm{H}), 6.97-6.90(\mathrm{~m}, 3 \mathrm{H}), 6.59(\mathrm{~d}$, $J=1.6 \mathrm{~Hz}, 2 \mathrm{H}), 5.78(\mathrm{~s}, 1 \mathrm{H}) ;{ }^{13} \mathrm{C} \mathrm{NMR}\left(\mathrm{CDCl}_{3}, 100 \mathrm{MHz}\right): \delta 158.52,156.38,141,53$, $136,70,133.44,129.09,129.03,126.75,123.59,122.20,120.73,119.69,119.48,118.92$, 116.17, 115.97, 111.16, 102.65, 39.30; IR $\left(\mathrm{CHCl}_{3}\right): v_{\max } 3401,1574,1384,1044 \mathrm{~cm}^{-1}$; ESI-MS: $\mathrm{m} / \mathrm{z} 419.0376[\mathrm{M}+1]^{+}, 457.0693[\mathrm{M}+\mathrm{K}]^{+}$; HRMS: $\mathrm{m} / \mathrm{z} 417.03937$ and 419.03801 calcd for $\mathrm{C}_{23} \mathrm{H}_{16} \mathrm{BrFN}_{2}-\mathrm{H}^{+}$(417.03972 and 419.03794).

4.2.3. 3,3'-(3-Bromophenyl-methanediyl)-bisindole (7i)—Black solid; m.p. 84-86 ${ }^{\circ} \mathrm{C} ;{ }^{1} \mathrm{H}$ NMR $\left(\mathrm{CDCl}_{3}, 400 \mathrm{MHz}\right): \delta 7.87$ (brs, $\left.2 \mathrm{H}\right), 7.43(\mathrm{~s}, 1 \mathrm{H}), 7.38-7.34(\mathrm{~m}, 4 \mathrm{H})$, 7.30-7.24 (m, 2H), 7.20-7.11 (m, 3H), 7.07 (t, J=7.5 Hz, 2H), $6.58(\mathrm{~s}, 2 \mathrm{H}), 5.78$ (s, $1 \mathrm{H}) ;{ }^{13} \mathrm{C} \mathrm{NMR}\left(\mathrm{CDCl}_{3}, 125 \mathrm{MHz}\right): \delta 146.50,136.61,131.68,129.80,129.30,127.39$, $126.78,123.69,122.38,122.05,119.77,119.40,118.88,110.84,39.89 ; \mathrm{IR}\left(\mathrm{CHCl}_{3}\right): v_{\max }$ 2912, 1612, 1509, 1455, 1217, $1039 \mathrm{~cm}^{-1}$; ESI-MS: $\mathrm{m} / \mathrm{z} 401$ [M+1] ${ }^{+}$; HRMS: $\mathrm{m} / \mathrm{z} 401.0457$ calcd for $\mathrm{C}_{23} \mathrm{H}_{17} \mathrm{BrN}_{2}+\mathrm{H}^{+}$(401.0474).

4.2.4. 5,5'-Diiodo-3,3'-(4-hydroxyphenyl-methanediyl)-bisindole (8a)—Dark maroon solid; m.p. $93-95{ }^{\circ} \mathrm{C} ;{ }^{1} \mathrm{H}$ NMR $\left(\mathrm{CDCl}_{3}, 400 \mathrm{MHz}\right): \delta 7.97$ (s, 2H), 7.67 (d, $J=1.2$ $\mathrm{Hz}, 2 \mathrm{H}), 7.43-7.40$ (q, $J=1.6,8.4 \mathrm{~Hz}, 2 \mathrm{H}), 7.15-7.12$ (q, $J=5.6,8.4 \mathrm{~Hz}, 4 \mathrm{H}), 6.77$ (d, $J=$ $6.8 \mathrm{~Hz}, 2 \mathrm{H}), 6.58(\mathrm{~d}, J=1.6 \mathrm{~Hz}, 2 \mathrm{H}), 5.67(\mathrm{~s}, 1 \mathrm{H}), 4.73(\mathrm{brs}, 1 \mathrm{H}, \mathrm{OH}) ;{ }^{13} \mathrm{C} \mathrm{NMR}\left(\mathrm{CDCl}_{3}\right.$, $125 \mathrm{MHz}$ ): $\delta 153.67,135.42,134.22,130.70,129.31,129.01,128.44,124.11,119.08$, 115.23, 112.95, 82.46, 38.62; IR $\left(\mathrm{CHCl}_{3}\right): \nu_{\max } 3422,2927,1612,1596,1510,1454,1215$, $1094 \mathrm{~cm}^{-1}$; ESI-MS: $\mathrm{m} / z$ 588.8 [M-1] ${ }^{+}$; HRMS: $\mathrm{m} / z 588.9251$ calcd for $\mathrm{C}_{23} \mathrm{H}_{16} \mathrm{I}_{2} \mathrm{~N}_{2} \mathrm{O}-\mathrm{H}^{+}$ (588.9268).

4.2.5. 5,5'-Diiodo-3,3'-(4-hydroxy-3-methoxyphenyl-methanediyl)-bisindole (8b) $-{ }^{1} \mathrm{H}$ NMR $\left(\mathrm{CDCl}_{3}, 400 \mathrm{MHz}\right): \delta 8.00(\mathrm{~s}, 2 \mathrm{H}), 7.69(\mathrm{~d}, J=1.2 \mathrm{~Hz}, 2 \mathrm{H}), 7.42-7.39$ (q, $J=$ $1.6,8.4 \mathrm{~Hz}, 2 \mathrm{H}), 7.13(\mathrm{~d}, J=8.8 \mathrm{~Hz}, 2 \mathrm{H}), 6.83(\mathrm{t}, J=8.4 \mathrm{~Hz}, 2 \mathrm{H}), 6.72(\mathrm{q}, J=1.6,8.0 \mathrm{~Hz}$, $1 \mathrm{H}), 6.56(\mathrm{~d}, J=1.6,2 \mathrm{H}), 5.67(\mathrm{~s}, 1 \mathrm{H}), 3.76(\mathrm{~s}, 3 \mathrm{H}) ; \mathrm{IR}\left(\mathrm{CHCl}_{3}\right): v_{\max } 3422,2927,1612$, 1596, 1510, 1454, 1315, $1094 \mathrm{~cm}^{-1}$; ESI-MS: $\mathrm{m} / \mathrm{z} 618.8$ [M-1] $]^{+}$; HRMS: $\mathrm{m} / z 618.9362$ calcd for $\mathrm{C}_{24} \mathrm{H}_{18} \mathrm{I}_{2} \mathrm{~N}_{2} \mathrm{O}-\mathrm{H}^{+} 2$ (618.9374).

4.2.6. 5,5'-Diiodo-3,3'-(4-fluoro-3-bromophenyl-methanediyl)-bisindole (8c)Brown crystalline solid; m.p. $145-147{ }^{\circ} \mathrm{C} ;{ }^{1} \mathrm{H} \mathrm{NMR}\left(\mathrm{CDCl}_{3}, 400 \mathrm{MHz}\right)$ : $\delta 8.02(\mathrm{~s}, 2 \mathrm{H}), 7.87$ (s, 1H), $7.53(\mathrm{~m}, 2 \mathrm{H}), 7.21-7.02(\mathrm{~m}, 6 \mathrm{H}), 6.75(\mathrm{~s}, 2 \mathrm{H}), 5.71(\mathrm{~s}, 1 \mathrm{H}) ;{ }^{13} \mathrm{C} \mathrm{NMR}\left(\mathrm{CDCl}_{3}, 100\right.$ MHz): $\delta 158.78,156.82,140.58,140.55,135.75,133.17,130.17,129.10,128.85,127.65$, 124.67, 117.97, 116.40, 116.22, 113.49, 113.25, 109.10, 108.93, 83.15, 38.80; IR $\left(\mathrm{CHCl}_{3}\right)$ : $v_{\max } 3428,2924,1595,1490,1455,1243,1045 \mathrm{~cm}^{-1}$; ESI-MS: $\mathrm{m} / z$ 668.8 [M-1] $]^{+}$HRMS: $\mathrm{m} / \mathrm{z} 670.8299$ calcd for $\mathrm{C}_{23} \mathrm{H}_{14} \mathrm{BrFI}_{2} \mathrm{~N}_{2}+\mathrm{H}^{+}(670.8312)$.

4.2.7. 5,5'-Diiodo-3,3'-(4-bromophenyl-methanediyl)-bisindole (8d)—Brown solid; m.p. $122-123{ }^{\circ} \mathrm{C} ;{ }^{1} \mathrm{H}$ NMR $\left(\mathrm{CDCl}_{3}, 400 \mathrm{MHz}\right): \delta 7.94$ (s, $\left.2 \mathrm{H}\right), 7.59(\mathrm{~d}, J=1.2 \mathrm{MHz}$, $2 \mathrm{H}), 7.38-7.34(\mathrm{~m}, 4 \mathrm{H}), 7.10-7.07(\mathrm{~m}, 4 \mathrm{H}) 6.52(\mathrm{~d}, J=1.6 \mathrm{~Hz}, 2 \mathrm{H}), 5.53(\mathrm{~s}, 1 \mathrm{H}) ;{ }^{13} \mathrm{C}$ NMR $\left(\mathrm{CDCl}_{3}, 125 \mathrm{MHz}\right): \delta 142.13,135.75,131.53,130.62,130.26,129.24,128.36,124.37$, 120.34, 118.18, 113.19, 83.06, 39.23; IR $\left(\mathrm{CHCl}_{3}\right): \nu_{\max } 3421,2922,1596,1457,1413$, $1021 \mathrm{~cm}^{-1}$; ESI-MS: $\mathrm{m} / z 650.8[\mathrm{M}-\mathrm{H}]^{+}$; HRMS: $\mathrm{m} / \mathrm{z} 650.8407$ calcd for $\mathrm{C}_{23} \mathrm{H}_{15} \mathrm{BrI}_{2} \mathrm{~N}_{2}-\mathrm{H}^{+}$ (650.8424).

4.2.8. 5,5'-Diiodo-3,3'-(2,6-dichlorophenyl-methanediyl)-bisindole (8e)-Maroon colored solid; m.p. $247-249{ }^{\circ} \mathrm{C} ;{ }^{1} \mathrm{H}$ NMR $\left(\mathrm{CDCl}_{3}, 400 \mathrm{MHz}\right): \delta 7.98(\mathrm{~s}, 2 \mathrm{H}), 7.57(\mathrm{~s}, 2 \mathrm{H})$, 7.38-7.33 (m, 3H), 7.14-7.08 (m, 4H), 6.74 (s, $2 \mathrm{H}), 6.59$ (s, 1H); ${ }^{13} \mathrm{C} \mathrm{NMR}\left(\mathrm{CDCl}_{3}, 125\right.$ MHz): $\delta 137.68,136.45,135.41,130.38,129.55,128.11,128.31,125.17,114.66,113.01$, 
83.12, 36.69; IR (CHCl3): $v_{\max } 3412,2926,1623,1582,1483,1453,1210 \mathrm{~cm}^{-1}$; ESI-MS: $\mathrm{m} / \mathrm{z} 640.8$ [M-H] $]^{+}$; HRMS: $\mathrm{m} / z 650.8526$ calcd for $\mathrm{C}_{23} \mathrm{H}_{14} \mathrm{Cl}_{2} \mathrm{I}_{2} \mathrm{~N}_{2}-\mathrm{H}^{+}(650.8540)$.

4.2.9. 5,5'-Diiodo-3,3'-(4-nitrophenyl-methanediyl)-bisindole (8g)—Orange crystalline solid; m.p. $144-146{ }^{\circ} \mathrm{C}$; ${ }^{1} \mathrm{H}$ NMR $\left(\mathrm{CDCl}_{3}, 400 \mathrm{MHz}\right): \delta 8.18(\mathrm{~d}, J=8.0 \mathrm{MHz}$, $2 \mathrm{H}), 8.10(\mathrm{~s}, 2 \mathrm{H}), 7.66(\mathrm{~d}, J=1.2 \mathrm{MHz}, 2 \mathrm{H}), 7.49-7.43(\mathrm{~m}, 4 \mathrm{H}), 7.22(\mathrm{~d}, J=8.4 \mathrm{MHz}, 2 \mathrm{H})$, $6.63(\mathrm{~d}, J=1.6 \mathrm{MHz}, 2 \mathrm{H}), 5.88(\mathrm{~s}, 1 \mathrm{H}) ;{ }^{13} \mathrm{C} \mathrm{NMR}\left(\mathrm{CDCl}_{3}, 125 \mathrm{MHz}\right): \delta 150.80,146.79$, $135.77,130.91,129.37,128.17,124.40,123.83,117.21,113.34,83.28,39.72 ;$ IR $\left(\mathrm{CHCl}_{3}\right)$ : $\nu_{\max } 3391,2923,1617,1401,1022 \mathrm{~cm}^{-1}$; ESI-MS: $\mathrm{m} / z 617.9[\mathrm{M}-\mathrm{H}]^{+}, 641.9[\mathrm{M}+\mathrm{Na}]^{+}$; HRMS: $m / z 617.9173$ calcd for $\mathrm{C}_{23} \mathrm{H}_{15} \mathrm{I}_{2} \mathrm{~N}_{3} \mathrm{O}_{2}-\mathrm{H}^{+}(617.9170)$.

4.2.10. 5,5'-Diiodo-3,3'-(naphth-1-yl-methanediyl)-bisindole (8h)-Maroon solid; m.p. 224-226 ${ }^{\circ} \mathrm{C} ;{ }^{1} \mathrm{H} \mathrm{NMR}\left(\mathrm{CDCl}_{3}, 400 \mathrm{MHz}\right): \delta 8.05$ (d, J = $\left.8.0 \mathrm{~Hz}, 1 \mathrm{H}\right), 7.99$ (brs, 2H), $7.91(\mathrm{~d}, \mathrm{~J}=8.0 \mathrm{~Hz}, 1 \mathrm{H}), 7.78(\mathrm{~d}, \mathrm{~J}=8.0 \mathrm{~Hz}, 1 \mathrm{H}), 7.70(\mathrm{~d}, \mathrm{~J}=1.2 \mathrm{~Hz}, 2 \mathrm{H}), 7.50-7.36(\mathrm{~m}$, $4 \mathrm{H}), 7.32(\mathrm{t}, \mathrm{J}=8.0 \mathrm{~Hz}, 2 \mathrm{H}), 7.18-7.13(\mathrm{~m}, 3 \mathrm{H}), 6.51(\mathrm{~s}, 1 \mathrm{H}), 6.51(\mathrm{~d}, \mathrm{~J}=2.4 \mathrm{~Hz}, 1 \mathrm{H}) ;{ }^{13} \mathrm{C}$ NMR $\left(\mathrm{CDCl}_{3}, 100 \mathrm{MHz}\right): \delta 138.60,135.85,134.06,131.65,130.55,129.47,128.74$, 128.36, 127.40, 126.04, 125.92, 125.44, 125.06, 124.13, 118.46, 113.18, 83.04, 35.54; IR $\left(\mathrm{CHCl}_{3}\right): v_{\max } 3389,1621,1384,1038 \mathrm{~cm}^{-1}$; ESI-MS: $\mathrm{m} / \mathrm{z} 623$ [M-1] ${ }^{+}$; HRMS: $\mathrm{m} / \mathrm{z}$ 622.9475 calcd for $\mathrm{C}_{27} \mathrm{H}_{18} \mathrm{I}_{2} \mathrm{~N}_{2}-\mathrm{H}^{+}(622.9476)$.

4.2.11. 5,5'-Diiodo-3,3'-(anthracen-10-yl-methanediyl)-bisindole (8i)-Brown solid; m.p. $121-123{ }^{\circ} \mathrm{C} ;{ }^{1} \mathrm{H}$ NMR $\left(\mathrm{CDCl}_{3}, 500 \mathrm{MHz}\right): \delta 8.54-8.48(\mathrm{~m}, 2 \mathrm{H}), 8.05-7.90(\mathrm{~m}$, 4H), $7.68(\mathrm{~s}, 1 \mathrm{H}), 7.50-7.25(\mathrm{~m}, 7 \mathrm{H}), 7.12(\mathrm{~d}, 5.2 \mathrm{~Hz}, 4 \mathrm{H}), 6.73(\mathrm{~s}, 1 \mathrm{H}), 6.71(\mathrm{~s}, 1 \mathrm{H}) ;{ }^{13} \mathrm{C}$ NMR (DMSO, $100 \mathrm{MHz}$ ): $\delta 135.10,134.67,133.13,132.75,130.77,129.35,128.89$, 128.66, 128.31, 127.72, 126.88, 123.66, 120.13, 117.01, 112.16, 111.57, 82.02, 81.78, 33.38; IR $\left(\mathrm{CHCl}_{3}\right): \nu_{\max } 3416,2927,1622,1582,1483,1453,1210,1172,1028 \mathrm{~cm}^{-1}$; ESIMS: $m / z 673[\mathrm{M}-1]^{+}$; HRMS: $m / z 672.9621$ calcd for $\mathrm{C}_{27} \mathrm{H}_{18} \mathrm{I}_{2} \mathrm{~N}_{2}-\mathrm{H}^{+}(672.9632)$.

4.2.12. 5,5'-Diiodo-3,3'-(5-nitrofuran-2-yl-methanediyl)-bisindole (8j)—Green crystalline solid; m.p. $121-123{ }^{\circ} \mathrm{C} ;{ }^{1} \mathrm{H}$ NMR $\left(\mathrm{CDCl}_{3}, 400 \mathrm{MHz}\right): \delta 8.15$ (s, $\left.2 \mathrm{H}\right), 7.75$ (s, 2H), $7.52(\mathrm{~m}, 2 \mathrm{H}), 7.21(\mathrm{t}, J=4 \mathrm{~Hz}, 1 \mathrm{H}), 7.20(\mathrm{~d}, J=8.4 \mathrm{~Hz}, 2 \mathrm{H}), 6.91(\mathrm{~d}, J=2.4 \mathrm{~Hz}, 2 \mathrm{H})$, $6.28(\mathrm{~d}, J=3.2 \mathrm{~Hz}, 2 \mathrm{H}), 5.86(\mathrm{~s}, 1 \mathrm{H}) ;{ }^{13} \mathrm{C} \mathrm{NMR}\left(\mathrm{CDCl}_{3}, 125 \mathrm{MHz}\right): \delta 160.19,135.63$, $130.98,128.63,127.90,124.15,113.62,113.46,112.78,110.83,83.45,34.40 ;$ IR $\left(\mathrm{CHCl}_{3}\right)$ : $\nu_{\max } 3418,2924,1584,1455,1242,1019,516 \mathrm{~cm}^{-1}$; ESI-MS: $\mathrm{m} / \mathrm{z} 608$ [M-H] ${ }^{+}$; HRMS: $\mathrm{m} /$ $z 607.8965$ calcd for $\mathrm{C}_{21} \mathrm{H}_{13} \mathrm{I}_{2} \mathrm{~N}_{3} \mathrm{O}_{3}-\mathrm{H}^{+}(607.8963)$.

4.2.13. 5,5'-Dimethoxy-3,3'-(4-hydroxyphenyl-methanediyl)-bisindole (9a)Dark maroon solid; m.p. $140-142{ }^{\circ} \mathrm{C} ;{ }^{1} \mathrm{H} \mathrm{NMR}\left(\mathrm{CDCl}_{3}, 400 \mathrm{MHz}\right): \delta 7.76(\mathrm{~s}, 2 \mathrm{H})$, 7.36-7.17 (m, 4H), 6.85-6.79 (m, 4H), $6.76(\mathrm{~d}, J=7.6 \mathrm{~Hz}, 2 \mathrm{H}), 6.65(\mathrm{~d}, J=1.6 \mathrm{~Hz}, 2 \mathrm{H})$, 5.70 (s, 1H), 4.70 (brs, 1H, OH), 3.69 (s, 6H); IR $\left(\mathrm{CHCl}_{3}\right): v_{\max } 3409,2927,1581,1482$, 1439, 1204, $1038 \mathrm{~cm}^{-1}$; ESI-MS: $\mathrm{m} / \mathrm{z} 397.2$ [M-H] $]^{+}$; HRMS: $\mathrm{m} / \mathrm{z} 397.1541$ calcd for $\mathrm{C}_{25} \mathrm{H}_{22} \mathrm{~N}_{2} \mathrm{O}_{3}-\mathrm{H}^{+}$(397.1547).

4.2.14. 5,5'-Dimethoxy-3,3'-(4-hydroxy-3-methoxyphenyl-methanediyl)bisindole (9b)—Dark violet solid; m.p. 88-90 ${ }^{\circ} \mathrm{C} ;{ }^{1} \mathrm{H} \mathrm{NMR}\left(\mathrm{CDCl}_{3}, 400 \mathrm{MHz}\right): \delta 7.83$ (s, $2 \mathrm{H}), 7.25(\mathrm{~m}, 2 \mathrm{H}), 6.87(\mathrm{~m}, 7 \mathrm{H}), 6.65(\mathrm{~d}, J=1.6 \mathrm{~Hz}, 2 \mathrm{H}), 5.69(\mathrm{~s}, 1 \mathrm{H}), 3.75(\mathrm{~s}, 3 \mathrm{H}), 3.70(\mathrm{~s}$, $6 \mathrm{H}) ; \mathrm{IR}\left(\mathrm{CHCl}_{3}\right): v_{\max } 3401,2957,2927,2856,1736,1584,1459,1267,1171,1030 \mathrm{~cm}^{-1}$; ESI-MS: $m / z 427$ [M-1] ${ }^{+}$; HRMS: $m / z 427.1654$ calcd for $\mathrm{C}_{26} \mathrm{H}_{24} \mathrm{~N}_{2} \mathrm{O}_{4}-\mathrm{H}^{+}$(427.1652).

4.2.15. 5,5'-Dimethoxy-3,3'-(4-fluoro-3-bromophenyl-methanediyl)-bisindole (9c)—Maroon solid; m.p. $93-95{ }^{\circ} \mathrm{C} ;{ }^{1} \mathrm{H} \mathrm{NMR}\left(\mathrm{CDCl}_{3}, 400 \mathrm{MHz}\right): \delta 7.78$ (brs, $\left.2 \mathrm{H}\right), 7.46$ (dd, $J=2.0,6.8 \mathrm{~Hz}, 1 \mathrm{H}), 7.27-7.23(\mathrm{~m}, 3 \mathrm{H}), 6.98(\mathrm{t}, J=8.4 \mathrm{~Hz}, 1 \mathrm{H}), 6.79(\mathrm{~d}, J=2.4 \mathrm{~Hz}$, 
$2 \mathrm{H}), 6.70(\mathrm{~s}, 2 \mathrm{H}), 6.58(\mathrm{~s}, 2 \mathrm{H}), 5.64(\mathrm{~s}, 1 \mathrm{H}), 3.64(\mathrm{~s}, 6 \mathrm{H}) ;{ }^{13} \mathrm{C} \mathrm{NMR}\left(\mathrm{CDCl}_{3}, 100 \mathrm{MHz}\right): \delta$ $158.80,156.37,153.89,141.47,133.47,131.90,129.09,127.21,124.45,118.47,116.15$, 112.10, 108.81, 101.82, 55.92, 39.36; IR $\left(\mathrm{CHCl}_{3}\right): v_{\max } 3412,2928,1584,1623,1487$, 1210, 1043, $1022 \mathrm{~cm}^{-1}$; ESI-MS: $\mathrm{m} / z 479[\mathrm{M}+1]^{+}, 501[\mathrm{M}+\mathrm{Na}]^{+}$; HRMS: $m / z 477.0590$ calcd for $\mathrm{C}_{25} \mathrm{H}_{20} \mathrm{BrFN}_{2} \mathrm{O}_{2}-\mathrm{H}^{+}$(477.0609).

4.2.16. 5,5'-Dimethoxy-3,3'-(2,6-dichlorophenyl-methanediyl)-bisindole (9e)Cream colored solid; m.p. $217-219{ }^{\circ} \mathrm{C} ;{ }^{1} \mathrm{H}$ NMR (DMSO-d 6 , $500 \mathrm{MHz}$ ): $\delta 7.88(\mathrm{~s}, 2 \mathrm{H})$, 7.33-7.28 (m, 4H), $7.16(\mathrm{t}, J=8.0 \mathrm{~Hz}, 1 \mathrm{H}), 6.92(\mathrm{~s}, 2 \mathrm{H}), 6.87-6.83(\mathrm{~m}, 4 \mathrm{H}), 6.74(\mathrm{~s}, 1 \mathrm{H})$, $5.11(\mathrm{~s}, 1 \mathrm{H}), 3.73(\mathrm{~s}, 6 \mathrm{H}) ;{ }^{13} \mathrm{C} \mathrm{NMR}\left(\mathrm{CDCl}_{3}, 125 \mathrm{MHz}\right): \delta 153.71,138.41,131.45,130.01$, $128.10,127.51,125.16,114.72,111.82,111.73,101.53,55.75,37.23 ; \mathrm{IR}\left(\mathrm{CHCl}_{3}\right): v_{\max }$ 3412, 2926, 1623, 1582, 1483, 1453, $1210 \mathrm{~cm}^{-1}$; ESI-MS: $\mathrm{m} / \mathrm{z} 451[\mathrm{M}+1]^{+}, 473[\mathrm{M}+\mathrm{Na}]^{+}$; HRMS: $m / Z 473.0800$ calcd for $\mathrm{C}_{25} \mathrm{H}_{20} \mathrm{Cl}_{2} \mathrm{~N}_{2} \mathrm{O}_{2}+\mathrm{Na}^{+}$(473.0794).

4.2.17. 5,5'-Dimethoxy-3,3'-(naphth-1-yl-methanediyl)-bisindole (9h)—Light brown solid; m.p. $233-235^{\circ} \mathrm{C}$; ${ }^{1} \mathrm{H}$ NMR $\left(\mathrm{CDCl}_{3}, 400 \mathrm{MHz}\right): \delta 8.16(\mathrm{~d}, J=8.0 \mathrm{~Hz}, 1 \mathrm{H}), 7.89$ $(\mathrm{d}, J=8.0 \mathrm{~Hz}, 1 \mathrm{H}), 7.80(\mathrm{~s}, 1 \mathrm{H}), 7.75(\mathrm{~d}, J=8.0 \mathrm{~Hz}, 1 \mathrm{H}), 7.46-7.40(\mathrm{~m}, 3 \mathrm{H}), 7.30-7.25(\mathrm{~m}$, $5 \mathrm{H}), 6.83(\mathrm{t}, J=6.4 \mathrm{~Hz}, 4 \mathrm{H}), 6.58(\mathrm{~d}, J=2.0 \mathrm{~Hz}, 1 \mathrm{H}), 6.52(\mathrm{~s}, 1 \mathrm{H}), 3.66(\mathrm{~s}, 6 \mathrm{H}) ;{ }^{13} \mathrm{C}$ NMR (DMSO-d 6 , $100 \mathrm{MHz}$ ): $\delta 152.73,140.24,133.59,131.88,131.38,128.50,127.01,126.51$, 125.70, 125.47, 125.24, 124.96, 124.14, 117.31, 112.06, 110.50, 101.43, 55.29, 35.49; IR $\left(\mathrm{CHCl}_{3}\right): \nu_{\max } 3389,1621,1384,1038 \mathrm{~cm}^{-1}$; ESI-MS: $\mathrm{m} / \mathrm{z} 433.2[\mathrm{M}+1]^{+}, 455.2[\mathrm{M}+\mathrm{Na}]^{+}$; HRMS: $m / z 455.1728$ calcd for $\mathrm{C}_{29} \mathrm{H}_{24} \mathrm{~N}_{2} \mathrm{O}_{2}+\mathrm{Na}^{+}(455.1730$ ).

4.2.18. 5,5'-Dimethoxy-3,3'-(anthracen-10-yl-methanediyl)-bisindole (9i)—Brown solid; m.p. $123-125{ }^{\circ} \mathrm{C} ;{ }^{1} \mathrm{H} \mathrm{NMR}\left(\mathrm{CDCl}_{3}, 500 \mathrm{MHz}\right): \delta 8.65(\mathrm{~d}, J=8.9 \mathrm{~Hz}, 1 \mathrm{H}), 8.44$ (s, $1 \mathrm{H}), 8.05$ (brs, 2H), 7.81 (brs, 2H), 7.56-7.51 (dd, $J=7.2,18.3 \mathrm{~Hz}, 1 \mathrm{H}), 7.39-7.04(\mathrm{~m}, 8 \mathrm{H})$, 6.97-6.67 (m, 4H), $6.49(\mathrm{~s}, 1 \mathrm{H}), 3.44(\mathrm{~s}, 6 \mathrm{H}) ;{ }^{13} \mathrm{C} \mathrm{NMR}\left(\mathrm{CDCl}_{3}, 125 \mathrm{MHz}\right): \delta 153.48$, $135.14,131.57,127.75,127.25,125.32,124.68,118.38,112.04,111.61,101.80,55.58$, 34.71; IR $\left(\mathrm{CHCl}_{3}\right): v_{\max } 3416,2927,1622,1582,1483,1453,1210,1172,1028 \mathrm{~cm}^{-1}$; ESIMS: $\mathrm{m} / \mathrm{z} 483.2[\mathrm{M}+1]^{+}, 505.2[\mathrm{M}+\mathrm{Na}]^{+}, 521.2[\mathrm{M}+\mathrm{K}]^{+}$; HRMS: $\mathrm{m} / \mathrm{z} 483.2041$ calcd for $\mathrm{C}_{33} \mathrm{H}_{26} \mathrm{~N}_{2} \mathrm{O}_{2}+\mathrm{H}^{+}$(483.2067).

4.2.19. 5,5'-Dimethoxy-3,3'-(thiophen-2-yl-methanediyl)-bisindole (9j)—Brown solid; m.p. $180-182{ }^{\circ} \mathrm{C} ;{ }^{1} \mathrm{H}$ NMR $\left(\mathrm{CDCl}_{3}, 400 \mathrm{MHz}\right): \delta 7.78(\mathrm{~s}, 2 \mathrm{H}), 7.18(\mathrm{~d}, \mathrm{~J}=8.0 \mathrm{~Hz}$, 2H), $7.08(\mathrm{t}, \mathrm{J}=4.0 \mathrm{~Hz}, 1 \mathrm{H}), 6.85(\mathrm{~d}, \mathrm{~J}=4.0 \mathrm{~Hz}, 2 \mathrm{H}), 6.81-6.75(\mathrm{~m}, 6 \mathrm{H}), 5.98(\mathrm{~s}, 1 \mathrm{H}), 3.64$ $(\mathrm{s}, 6 \mathrm{H}) ;{ }^{13} \mathrm{C} \mathrm{NMR}\left(\mathrm{CDCl}_{3}, 125 \mathrm{MHz}\right): \delta 153.81,148.22,131.75,127.72,127.20,125.16$, 123.96, 123.63, 119.27, 11.198, 11.70, 56.13, 34.79; IR $\left(\mathrm{CHCl}_{3}\right): v_{\max } 2926,2515,1622$, 1590, 1445, 1314, 1214, $1110 \mathrm{~cm}^{-1}$; ESI-MS: m/z 387.1 [M-1] ; HRMS: m/z 387.1147 calcd for $\mathrm{C}_{23} \mathrm{H}_{20} \mathrm{~N}_{2} \mathrm{O}_{2} \mathrm{~S}-\mathrm{H}^{+}$(387.1162).

\subsubsection{5,5'-Dimethoxy-3,3'-(5-nitrofuran-2-yl-methanediyl)-bisindole (9k)-} Green solid; m.p. $169-171^{\circ} \mathrm{C}$; ${ }^{1} \mathrm{H}$ NMR $\left(\mathrm{CDCl}_{3}, 400 \mathrm{MHz}\right): \delta 7.91(\mathrm{~s}, 2 \mathrm{H}), 7.23(\mathrm{~m}, 2 \mathrm{H})$, $6.88(\mathrm{~s}, 2 \mathrm{H}), 6.83-6.79(\mathrm{~m}, 4 \mathrm{H}), 6.72(\mathrm{~s}, 1 \mathrm{H}), 6.25(\mathrm{~d}, J=4.0 \mathrm{~Hz}, 1 \mathrm{H}), 5.81(\mathrm{~s}, 1 \mathrm{H}), 3.69$ (s, $6 \mathrm{H}) ;{ }^{13} \mathrm{C} \mathrm{NMR}\left(\mathrm{CDCl}_{3}, 125 \mathrm{MHz}\right): \delta 160.19,135.63,130.98,128.63,127.90,124.15$, 113.62, 113.46, 112.78, 110.83, 83.45, 34.40; IR $\left(\mathrm{CHCl}_{3}\right): v_{\max } 3418,2924,1584,1455$, 1305, 1242, $1019 \mathrm{~cm}^{-1}$; ESI-MS: $\mathrm{m} / \mathrm{z} 418[\mathrm{M}+1]^{+}, 440[\mathrm{M}+\mathrm{Na}]^{+}, 456[\mathrm{M}+\mathrm{K}]^{+}$; HRMS: $\mathrm{m} / \mathrm{z}$ 418.1395 calcd for $\mathrm{C}_{23} \mathrm{H}_{19} \mathrm{~N}_{3} \mathrm{O}_{5}+\mathrm{H}^{+}$(418.1398).

\subsection{Fe-PILC: Preparation, characterization and recyclability}

Ferric chloride $\left(\mathrm{FeCl}_{3}\right)$ was used in Fe-PILC synthesis. A base-hydrolyzed $\mathrm{FeCl}_{3}$ pillaring solution was prepared using $\mathrm{OH} / \mathrm{Fe}$ molar ratio of 2.0. The hydrolysis was carried out at room temperature for $16 \mathrm{~h}$ under continuous stirring. Montmorillonite clay K10 powder was 
added gradually to Fe pillared solution, providing a required mmol of Fe per gram of clay. Fe Pillared clay suspension was stirred for $3 \mathrm{~h}$ at room temperature to allow ion exchange between exchangeable cations of the clay and pillar precursors. The formed PILCs were centrifuged, washed, dried in air, and calcined in air at $425^{\circ} \mathrm{C}$ for $3 \mathrm{~h}$.

Synthesized Fe-PILC catalyst was characterized using specific surface area determination, temperature programmed reduction (TPR), temperature programmed desorption (TPD) and scanning electron microscopy (SEM). The specific surface areas $\left(\mathrm{m}^{2} \mathrm{~g}^{-1}\right)$ of samples were estimated with the $\mathrm{N}_{2}$ adsorption at the liquid nitrogen temperature on the Quantachrom Chem-BET 3000. Temperature programmed reduction (TPR) profiles of catalyst precursors were collected on the Quantachrom Chem-BET 3000 apparatus equipped with a thermal conductivity detector (TCD). $50 \mathrm{mg}$ samples placed in a quartz U-shaped tube were reduced in $5 \% \mathrm{H}_{2} / \mathrm{N}_{2}$ flow $\left(80 \mathrm{~mL} \mathrm{~min}^{-1}\right)$ from room temperature to $700{ }^{\circ} \mathrm{C}$ at a temperature rise of 5 ${ }^{\circ} \mathrm{C} \mathrm{min}^{-1}$. Samples were pretreated in $\mathrm{N}_{2}$ flow $\left(50 \mathrm{~mL} \mathrm{~min}^{-1}\right)$ at $300{ }^{\circ} \mathrm{C}$ for $2 \mathrm{~h}$ to remove the adsorbed water and other contaminants prior to each TPR experiment.

The total acidity and acid distribution of the pillared clays was determined by ammonia TPD with the help of a CHEM BET-3000 (Quantachrome, USA) instrument in the temperature range of $30-800{ }^{\circ} \mathrm{C}$ [53]. About $0.1 \mathrm{~g}$ of powdered sample was taken inside a quartz $\mathrm{U}$ tube and degassed at $350{ }^{\circ} \mathrm{C}$ for $1 \mathrm{~h}$ with ultrapure helium gas. After the sample was cooled to room temperature, $\mathrm{NH}_{3}$ gas of $1000 \mathrm{ppm}$ with $\mathrm{N}_{2}$ gas was passed through the sample for 1 h. Then the ammonia adsorbed sample was purged with helium gas at $40{ }^{\circ} \mathrm{C}$ to remove any weakly adsorbed $\mathrm{NH}_{3}$ on the surface. The temperature-programmed desorption of ammonia was performed between 80 and $800{ }^{\circ} \mathrm{C}$ at $10^{\circ} \mathrm{C} / \mathrm{min}$. The morphology of Fe-PILC B catalyst was studied using JEOL.JEM100CXII electron microscope with ASID accelerating voltage of $40 \mathrm{KV}$.

Recyclability of the Fe-PILC $\mathbf{B}$ was checked using a model reaction between $1 H$-indole (5a) and 4-hydroxy benzaldehyde (6a). To the solution of indole $\mathbf{5 a}$ and aldehyde $\mathbf{6} \mathbf{a}$ in water was added $15 \mathrm{~mol} \% \mathrm{Fe}$-PILC B and reaction mixture was stirred at room temperature for 6 h. After completion of reaction, catalyst was recovered by filtration followed by washing with water. Recovered catalyst was dried in oven and reused in next cycle. The catalyst was recycled 3 times and the amount of catalyst recovered and percentage yield of the diindolylmethane $\mathbf{7 a}$ were determined.

\subsection{Assay for in vitro antileishmanial activity [54]}

The assays for in vitro antileishmanial activity on cultures of Leishmania donovani promastigotes and axenic amastigotes were carried out in 96-well plates as reported earlier [55-58]. The promastigotes culture was maintained at $26^{\circ} \mathrm{C}$ in RPMI $1640 \mathrm{pH} 7.4$ with $10 \%$ FBS. The axenic amastigotes were cultured at $37^{\circ} \mathrm{C} \& 5 \% \mathrm{CO}_{2}$ in RPMI- 1640 fortified with 4-Morpholineethanesulfonic acid (MES) (4.88 g/L), L-glutamine (298.2 mg/L), Adenosine $(26.7 \mathrm{mg} / \mathrm{L})$, Folic acid $(10.1 \mathrm{mg} / \mathrm{L})$, BME Vitamin mix, Sodium Bicarbonate $(352.8 \mathrm{mg} / \mathrm{L})$ and $10 \%$ FBS. The $\mathrm{pH}$ of the culture medium was 5.5. Compounds at various concentrations were added to the culture of Leishmania promastigotes or axenic amastigotes $\left(2 \times 10^{6}\right.$ cells/ $\mathrm{mL}$ ). Plates were incubated at $26^{\circ} \mathrm{C}$ for promastigotes and $37^{\circ} \mathrm{C} / 5 \% \mathrm{CO}_{2}$ for axenic amastigotes for $72 \mathrm{hrs}$ and growth of Leishmania promastigotes/amastigotes was determined by Alamar Blue Assay $[54,58]$. Pentamidine and amphotericin B were used as standard drugs. $\mathrm{IC}_{50}$ values were computed from growth inhibition curves.

\subsection{Assay for in vitro antimalarial activity [36]}

The assay is based on the determination of plasmodial LDH activity. For the assay, a suspension of red blood cells infected with D6 or W2 strains of P. falciparum $(200 \mu \mathrm{L}$, with 
$2 \%$ parasitemia and 2\% hematocrit in RPMI 1640 medium supplemented with $10 \%$ human serum and $60 \mu \mathrm{g} / \mathrm{mL}$ Amikacin) was added to the wells of a 96-well plate containing $10 \mu \mathrm{L}$ of test samples diluted in medium at various concentrations. The plate was placed in a modular incubation chamber (Billups-Rothenberg, CA) flushed with a gas mixture of $90 \%$ $\mathrm{N}_{2}, 5 \% \mathrm{O}_{2}$, and $5 \% \mathrm{CO}_{2}$ and incubated at $37{ }^{\circ} \mathrm{C}$, for $72 \mathrm{~h}$. Parasitic $\mathrm{LDH}$ activity was determined by using Malstat ${ }^{\mathrm{TM}}$ reagent (Flow Inc., Portland, OR) according to the procedure of Makler and Hinrichs [36]. Briefly, $20 \mu \mathrm{L}$ of the incubation mixture was mixed with 100 $\mu \mathrm{L}$ of the Malstat ${ }^{\mathrm{TM}}$ reagent and incubated at room temperature for $30 \mathrm{~min}$. Twenty microliters of a 1:1 mixture of NBT/PES (Sigma, St. Louis, MO) was then added and the plate is further incubated in the dark for $1 \mathrm{~h}$. The reaction was then stopped by the addition of $100 \mu \mathrm{L}$ of a $5 \%$ acetic acid solution. The plate was read at $650 \mathrm{~nm}$ using the EL-340 Biokinetics Reader (Bio-Tek Instruments, Vermont). $\mathrm{IC}_{50}$ values were computed from the dose response curves. Artemisinin and chloroquine were included in each assay as the drug controls. DMSO (0.25\%) was used as vehicle control [55-57].

\subsection{Assay for in vitro antimicrobial activity}

Microorganisms [fungi, Candida albicans (ATCC 90028), Candida krusei (ATCC 6258), Candida glabrata (ATCC 90030), Cryptococcus neoformans (ATCC 90113), and Aspergillus fumigatus (ATCC 204305) and bacteria, Staphylococcus aureus (ATCC 29213), methicillin-resistant $S$. aureus (MRSA, ATCC 33591), Escherichia coli (ATCC 35218), Pseudomonas aeruginosa (ATTCC 27853), and Mycobacterium intracellulare (ATCC 23068)] were obtained from ATCC. For all organisms, excluding $M$. intracellulare and $A$. fumigatus, susceptibility test was performed using a modified version of the CLSI (formerly NCCLS) methods [38, 39], and optical density was used to monitor growth. Media supplemented with 5\% Alamar Blue (BioSource International) was utilized for growth detection of $M$. intracellulare [40] and A. fumigatus [37]. Concentrations that afford 50\% inhibition $\left(\mathrm{IC}_{50} \mathrm{~s}\right)$ relative to controls were calculated using XLfit 4.2 software (IDBS) using fit model 201 based on duplicate readings. Minimum fungicidal or bactericidal concentrations were determined by removing $5 \mu \mathrm{L}$ from each clear well, transferring to agar, and incubating until growth was seen. Drug controls ciprofloxacin (ICN Biomedicals, 99.3\% purity) for bacteria and amphotericin B (ICN Biomedicals, 94.8\% purity) for fungi were included in each assay.

\subsection{Cytotoxicity assay}

The in vitro cytotoxicity was determined against mammalian kidney fibroblasts (VERO) and kidney epithelial (LLC-PK 1 ) cells. The assay was performed in 96-well tissue culturetreated plates as described earlier [58]. Briefly, cells were seeded to the wells of the plate $(25,000$ cells/well $)$ and incubated for $24 \mathrm{~h}$. Samples were added and plates were again incubated for $48 \mathrm{~h}$. The number of viable cells was determined by neutral red assay. $\mathrm{IC}_{50}$ values were determined from logarithmic graphs of growth inhibition versus concentration. Doxorubicin was used as a positive control, while DMSO was used as vehicle control.

\section{Supplementary Material}

Refer to Web version on PubMed Central for supplementary material.

\section{Acknowledgments}

RM and RRY thanks CSIR (India) for award of Senior Research Fellowship. Authors are thankful to analytical department, IIIM for NMR, MS and IR analysis of our compounds. Surendra Jain, Marsha Wright and John Trott are acknowledged for technical support in biological activity testing at NCNPR. United States Department of Agriculture (USDA), Agricultural Research Service Specific Cooperative Agreement No. 58-6408-2-0009 and US 
Department of Defense CDMRP grant \# W81XWH-09 (BLT) are acknowledged for partial support of this work. Antifungal testing was supported by NIH, NIAID, Division of AIDS grant \# AI27094.

\section{References}

[1]. Renslo AR, McKerrow JH. Drug discovery and development for neglected parasitic diseases. Nature Chem. Biol. 2006; 2:701-710. [PubMed: 17108988]

[2]. Kumar R, Nylén S. Immunobiology of visceral leishmaniasis. Front. Immunol. 2012; 3:251. [PubMed: 22912637]

[3]. Freitas-Junior LH, Chatelain E, Kim HA, Siqueira-Neto JL. Visceral leishmaniasis treatment: What do we have, what do we need and how to deliver it? Int. J. Parasitol.: Drugs and Drug Resistance. 2012; 2:11-19.

[4]. Muniaraj M, Paramasivan R, Mariappan T, Arunachalam N, Sinha PK. The treatment of visceral leishmaniasis (kala-azar) in India: no obvious signs of long-term success. Trans. Royal Soc. Trop. Med. Hyg. 2012; 106:770-772.

[5]. Castañon A, Tristram A, Mesher D, Powell N, Beer H, Ashman S, Rieck G, Fielder H, Fiander A, Sasieni P. Effect of diindolylmethane supplementation on low-grade cervical cytological abnormalities: double-blind, randomised, controlled trial. Br. J. Cancer. 2012; 106:45-52. [PubMed: 22075942]

[6]. Sharma DK, Rah B, Lambu MR, Hussain A, Yousuf SK, Tripathi AK, Singh B, Jamwal G, Ahmed Z, Chanauria N, Nargotra A, Goswami A, Mukherjee D. Design and synthesis of novel N,N'-glycoside derivatives of 3,3' -diindolylmethanes as potential antiproliferative agents. Med. Chem. Commun. 2012; 3:1082-1091.

[7]. Kamal A, Srikanth YVV, Ramaiah MJ, Khan MNA, Reddy MK, Ashraf M, Lavanya A, Pushpavalli SNCVL, Pal-Bhadra M. Synthesis, anticancer activity and apoptosis inducing ability of bisindole linked pyrrolo[2,1-c][1,4]benzodiazepine conjugates. Bioorg. Med. Chem. Lett. 2012; 22:571-578. [PubMed: 22104151]

[8]. Oh K-B, Mar W, Kim S, Kim J-Y, Lee T-H, Kin J-G, Shin D, Sim CJ, Shin J. Antimicrobial activity and cytotoxicity of bis(indole) alkaloids from the sponge Spongosorites sp. Biol. Pharm. Bull. 2006; 29:570-573. [PubMed: 16508170]

[9]. Mansouri MD, Opperman TJ, Williams JD, Stager C, Darouiche RO. In vitro potency and in vivo efficacy of a novel bis-indole antimicrobial compound in reducing catheter colonization. Antimicrob. Agents Chemother. 2012; 56:2201-2204. [PubMed: 22271864]

[10]. Mitchell, SS.; Lam, KS.; Grodberg, J.; Potts, BC.; Tsueng, G.; White, DJ.; Reed, KA. Bis-indole pyrroles useful as antimicrobials agents. Nereus Pharmaceuticals, Inc.; 2008 . US7375129

[11]. Gunasekera SP, McCarthy PJ, Kelly-Borges M. Hamacanthins A and B, new antifungal bis indole alkaloids from the deep-water marine sponge, Hamacantha Sp. J. Nat. Prod. 1994; 57:1437-1441. [PubMed: 7807127]

[12]. Martinez R, Espinosa A, Tarraga A, Molina P. Bis(indolyl)methane derivatives as highly selective colourimetric and ratiometric fluorescent molecular chemosensors for $\mathrm{Cu}^{2+}$ cations. Tetrahedron. 2008; 64:2184-2191.

[13]. Mishra BB, Kale RR, Singh RK, Tiwari VK. Alkaloids: Future prospective to combat leishmaniasis. Fitoterapia. 2009; 80:81-90. [PubMed: 19015012]

[14]. Singh GS, Al-kahraman YMSA, Mpadi D, Yasinzai M. Synthesis of N-(1-methyl-1H-indol-3yl)methyleneamines and 3,3-diaryl-4-(1-methyl-1H-indol-3-yl)azetidin-2-ones as potential antileishmanial agents. Bioorg. Med. Chem. Lett. 2012; 22:5704-5706. [PubMed: 22832310]

[15]. Staerk D, Lemmich E, Christensen J, Kharazmil A, Olsen CE, Jaroszewski JW. Leishmanicidal, antiplasmodial and cytotoxic activity of indole alkaloids from Corynanthe pachyceras. Planta Med. 2000; 66:531-536. [PubMed: 10985079]

[16]. Delorenzi JC, Attias M, Gattass CR, Abdrade M, Rezende C, Cunha-Pinto A, Henrique AT, BouHabib DC, Saraiva EM. Antileishmanial activity of an indole alkaloid from Peschiera australis. Antimicrob. Agents Chemother. 2001; 45:1349-1354. [PubMed: 11302794]

[17]. Tanaka JCA, Silva C.C.d. Ferreira ICP, Machado GMC, Leon LL, Oliveira A.J.B.d. Antileishmanial activity of indole alkaloids from Aspidosperma ramiflorum. Phytomedicine. 2007; 14:377-380. [PubMed: 17140782] 
[18]. Munoz V, Moretii C, Sauvain M, Caron C, Prozel A, Massiot G, Richard B, Le Men-Olivier L. Isolation of bis-indole alkaloids with antileishmanial and antibacterial activities from Peschiera var heurkii (Syn. Tabernaemontana var heurkii). Planta Med. 1994; 60:455-459. [PubMed: 7997477]

[19]. Sashidhara KV, Kumar A, Kumar M, Srivastava A, Puri A. Synthesis and antihyperlipidemic activity of novel coumarin bisindole derivatives. Bioorg. Med. Chem. Lett. 2010; 20:6504-6507. [PubMed: 20932744]

[20]. Lee SO, Abdelrahim M, Yoon K, Chintharlapalli S, Papineni S, Kim K, Wang H, Safe S. Inactivation of the orphan nuclear receptor TR3/Nur77 inhibits pancreatic cancer cell and tumor growth. Cancer Res. 2010; 70:6824-6836. [PubMed: 20660371]

[21]. Azizi N, Torkian L, Saidi MR. Highly efficient synthesis of bis(indolyl)methanes in water. J. Mol. Catal. A: Chem. 2007; 275:109-112.

[22]. Pasha MA, Jayashankara VP. p-Toluenesulfonic acid (p-TSA) catalyzed efficient synthesis of bis(indolyl)methanes under grindstone method. J. Pharmacol. Toxicol. 2006; 1:585-590.

[23]. Ramesh C, Banerjee J, Pal R, Das B. Silica supported sodium hydrogen sulfate and amberlyst-15: Two efficient heterogeneous catalysts for facile synthesis of bis- and tris(1H-indol-3-yl)methanes from indoles and carbonyl compounds. Adv. Synth. Catal. 2003; 345:557-559.

[24]. Farhanullah, A. Sharon; Maulik, PR.; Ram, VJ. Amberlist 15 catalyzed synthesis of indolepyrazole based tri(hetero)arylmethanes. Tetrahedron Lett. 2004; 45:5099-5102.

[25]. Aliyan H, Fazaeli R, Naghash HJ, Massah AR, Momeni AR, Iravani Z. Bulk and supported tungstophosphoric acid as friendly, efficient, recyclable catalysts for the synthesis of bisindolylmethanes under solvent-free conditions. Heteroatom Chem. 2009; 20:325-331.

[26]. Palaniappan S, Saravanan C, Rao VJ. Synthesis of polyaniline-bismoclite composite and its function as recoverable and reusable catalyst. J. Mol. Catal. A: Chem. 2005; 229:221-226.

[27]. Karthik M, Magesh CJ, Perumal PT, Palanichamy M, Arabindoo B, Murugesan V. Zeolitecatalyzed ecofriendly synthesis of vibrindole A and bis(indolyl)methanes. Appl. Catal. A: General. 2005; 286:137-141.

[28]. Karthik M, Tripathi AK, Gupta NM, Palanichamy M, Murugesan V. Zeolite catalyzed electrophilic substitution reaction of indoles with aldehydes: synthesis of bis(indolyl)methanes. Catal. Commun. 2004; 5:371-375.

[29]. Mudududdla R, Jain SK, Bharate JB, Gupta AP, Singh B, Vishwakarma RA, Bharate SB. OrthoAmidoalkylation of phenols via tandem one-pot approach involving oxazine intermediate. J. Org. Chem. 2012; 77:8821-8827. [PubMed: 22970791]

[30]. Mohammed S, Padala AK, Dar BA, Singh B, Sreedhar B, Vishwakarma RA, Bharate SB. Recyclable clay supported $\mathrm{Cu}$ (II) catalyzed tandem one-pot synthesis of 1-aryl-1,2,3-triazoles. Tetrahedron. 2012; 68:8156-8162.

[31]. Bharate SB, Mudududdla R, Bharate JB, Battini N, Battula S, Yadav RR, Singh B, Vishwakarma RA. Tandem one-pot synthesis of flavans by recyclable silica-HClO4 catalyzed Knoevenagel condensation and [4 + 2]-Diels-Alder cycloaddition. Org. Biomol. Chem. 2012; 10:5143-5150. [PubMed: 22648274]

[32]. Yadav RR, Battini N, Mudududdla R, Bharate JB, Muparappu N, Bharate SB, Vishwakarma RA. Deformylation of indole and azaindole-3-carboxaldehydes using anthranilamide and solid acid heterogeneous catalyst via quinazolinone intermediate. Tetrahedron Lett. 2012; 53:2222-2225.

[33]. Bharate SB, Manda S, Mupparapu N, Battini N, Vishwakarma RA. Chemistry and biology of fascaplysin, a potent marine-derived CDK-4 inhibitor. Mini Rev. Med. Chem. 2012; 12:650-664. [PubMed: 22512549]

[34]. Bharate SB, Yadav RR, Battula S, Vishwakarma RA. Meridianins: Marine-derived potent kinase inhibitors. Mini Rev. Med. Chem. 2012; 12:618-631. [PubMed: 22512550]

[35]. Bharate SB, Manda S, Joshi P, Singh B, Vishwakarma RA. Total synthesis and anticholinesterase activity of marine-derived bis-indole alkaloid fascaplysin. Med. Chem. Commun. 2012; 3:10981103.

[36]. Makler MT, Hinrichs DJ. Measurement of the lactate dehydrogenase activity of Plasmodium falciparum as an measurement of parasitemia. Am. J. Trop. Med. Hyg. 1993; 48:205-210. [PubMed: 8447524] 
[37]. NCCLS. Proposal standard M38-P. Vol. vol. 18. National Committee for Clinical Laboratory Standards; Wayne: 1998. Reference method for both dilution antifungal susceptibility testing of conidium forming filamentous fungi; p. 1039

[38]. NCCLS. NCCLS Document M7-A5. Vol. vol. 20. National Committee for Clinical Laboratory Standards; 2000. Methods for dilution antimicrobial susceptibility tests for bacteria that grow aerobically; p. 1-58.

[39]. NCCLS. Reference method for broth dilution antifungal susceptibility testing of yeasts. 2nd ed. Vol. vol. 22. National Committee for Clinical Laboratory Standards, Approved standard; 2002. p. $1-51.2$ nd ed

[40]. NCCLS. Nocardia, and other aerobic actinomycetes. 2nd ed. Vol. vol. 20. Tentative standard M24-T2, National Committee for Clinical Laboratory Standards; Wayne: 2000. Susceptibility testing of mycobacteria; p. 1-81.

[41]. Bharate SB, Singh B, Bharate JB, Jain SK, Meena S, Vishwakarma RA. QSAR and pharmacophore modeling of N-acetyl-2-aminobenzothiazole class of phosphoinositide-3-kinasealpha inhibitors. Med. Chem. Res. 2013; 22:890-899.

[42]. Bharate SB, Yadav RR, Vishwakarma RA. QSAR and pharmacophore study of Dyrk1A inhibitory meridianin analogs as potential agents for treatment of neurodegenerative diseases. Med. Chem. 2012; 9:152-161. [PubMed: 22920091]

[43]. Kamal A, Khan MNA, Reddy KS, Srikanth YVV, Ahmed SK, Kumar KP, Murthy USN. An efficient synthesis of bis(indolyl)methanes and evaluation of their antimicrobial activities. J. Enz. Inh. Med. Chem. 2009; 24:559-565.

[44]. Kidwai M, Bura N, Mishra NK. Niobium(V) pentachloride catalyzed efficient and highly rapid synthesis of bis(indolyl)-methanes under mild conditions. Indian J. Chem. 2011; 50B:229-232.

[45]. Ji SJ, Zhou MF, Gu DG, Jiang Z-Q, Loh TP. Efficient Fe-III-catalyzed synthesis of bis(indolyl)methanes in ionic liquids. Eur. J. Org. Chem. 2004:1584.

[46]. Magesh CJ, Nagarajan R, Karthik M, Perumal PT. Synthesis and characterization of bis(indolyl)methanes, tris(indolyl)methanes and new diindolylcarbazolylmethanes mediated by Zeokarb-225, a novel, recyclable, eco-benign heterogenous catalyst. Appl. Catal. A: General. 2004; 266:1-10.

[47]. Niknam K, Zolfigol MA, Sadabadi T, Nejati A. Preparation of indolylmethanes catalyzed by metal hydrogen sulfates. J. Iranian Chem. Soc. 2006; 3:318-322.

[48]. Lin X-F, Cui S-L, Wang Y-G. Mild and efficient synthesis of bis-indolylmethanes catalyzed by tetrabutylammonium tribromide. Synth. Commun. 2006; 36:3153-3160.

[49]. Maciejewska D, Rasztawicka M, Wolska I, Anuszewska E, Gruber B. Novel 3,3' diindolylmethane derivatives: Synthesis and cytotoxicity, structural characterization in solid state. Eur. J. Med. Chem. 2009; 44:4136-4147. [PubMed: 19540023]

[50]. Vahdat SM, Khaksar S, Baghery S. Sulfonated organic heteropolyacid salts: Recyclable green solid catalysts for the highly efficient and green synthesis of bis(indolyl)methanes in water. Lett. Org. Chem. 2012; 9:138-144.

[51]. Zhang D-M, Tang Q-G, Ji C-X, Guo C. 3,3' -(4-Bromophenylmethanediyl)bis(5-methoxy-1Hindole). Acta Crystallogr., Sect. E. 2007; E63:081-082.

[52]. Ke BW, Qin Y, Wang Y, Wang F. Amberlyst-catalyzed reaction of indole: Synthesis of bisindolylalkane. Synth. Commun. 2005; 35:1209-1212.

[53]. Singh B, Roy SK, Sharma KP, Goswami TK. Role of acidity of pillared inter-layered clay (PILC) for the synthesis of pyridine bases. J. Chem. Technol. Biotechnol. 1998; 71:246-252.

[54]. Mikus J, Steverding D. A simple colorimetric method to screen drug cytotoxicity against Leishmania using the dye Alamar Blue. Parasitol. Int. 2000; 48:265-269. [PubMed: 11227767]

[55]. Kumarihamy M, Khan SI, Jacob M, Tekwani BL, Duke SO, Ferreira D, Nanayakkara NPD. Antiprotozoal and antimicrobial compounds from the plant pathogen Septoria pistaciarum. J. Nat. Prod. 2012; 75:883-889. [PubMed: 22530813]

[56]. Machumi F, Yenesew A, Midiwo JO, Heydenreich M, Kleinpeter E, Tekwani BL, Khan SI, Walker LA, Muhammad I. Antiparasitic and anticancer carvotacetone derivatives of Sphaeranthus bullatus. Nat. Prod. Commun. 2012; 7:1123-1126. [PubMed: 23074885] 
[57]. Rahman AA, Samoylenko V, Jacob MR, Sahu R, Jain SK, Khan SI, Tekwani BL, Muhammad I. Antiparasitic and antimicrobial indolizidines from the leaves of Prosopis glandulosa var. glandulosa. Planta Med. 2011; 77:1639-1643. [PubMed: 21384317]

[58]. Mustafa J, Khan SI, Ma G, Walker LA, Khan IA. Synthesis and anticancer activities of FA analogs of podophyllotoxin. Lipids. 2004; 39:167-172. [PubMed: 15134144] 


\section{Highlights}

- We report discovery of $3,3^{\prime}$-diindolyl methanes as a new class of antileishmanial agents.

- Nitrofuryl linked 3,3'-diindolylmethane is most potent antileishmanial compound.

- An efficient protocol for synthesis of 3,3'-diindolyl methanes using recyclable Fe-PILC catalyst is described.

- Detailed SAR and pharmacophore based QSAR has been investigated.

- Promising antifungal activity against Cryptococcus neoformans was also observed. 


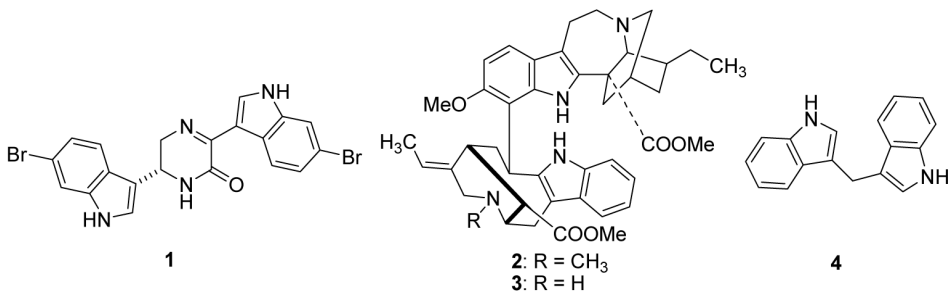

Figure 1.

Structures of biologically active bisindole alkaloids 1-4 


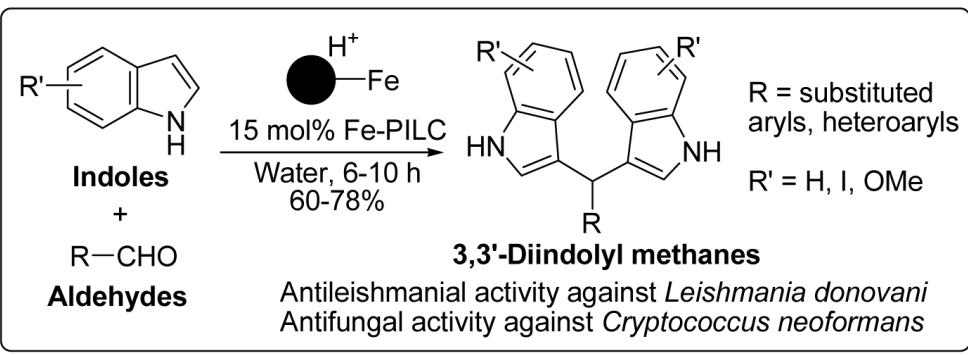

Figure 2.

Synthesis of $3,3^{\prime}$-diindolylmethanes using Fe-PILC catalyst 


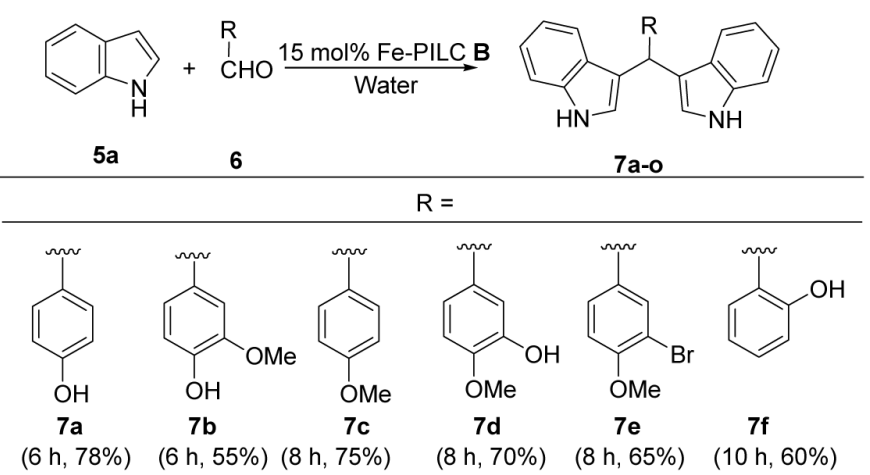

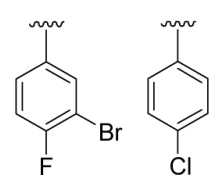

7 g $7 \mathrm{~h}$ $(6 \mathrm{~h}, 65 \%) \quad(6 \mathrm{~h}, 70 \%)$

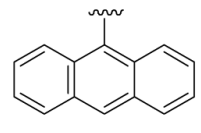

$7 \mathrm{~m}$

(8 h, 60\%)
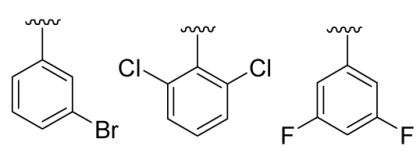

7k $(6 \mathrm{~h}, 68 \%)(10 \mathrm{~h}, 69 \%)$

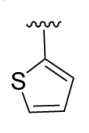

$7 n$ (6 h, 74\%)

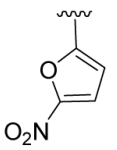

70

$(6,72 \%)$

Figure 3.

Synthesis of 3,3' -diindolylmethanes 7a-o 

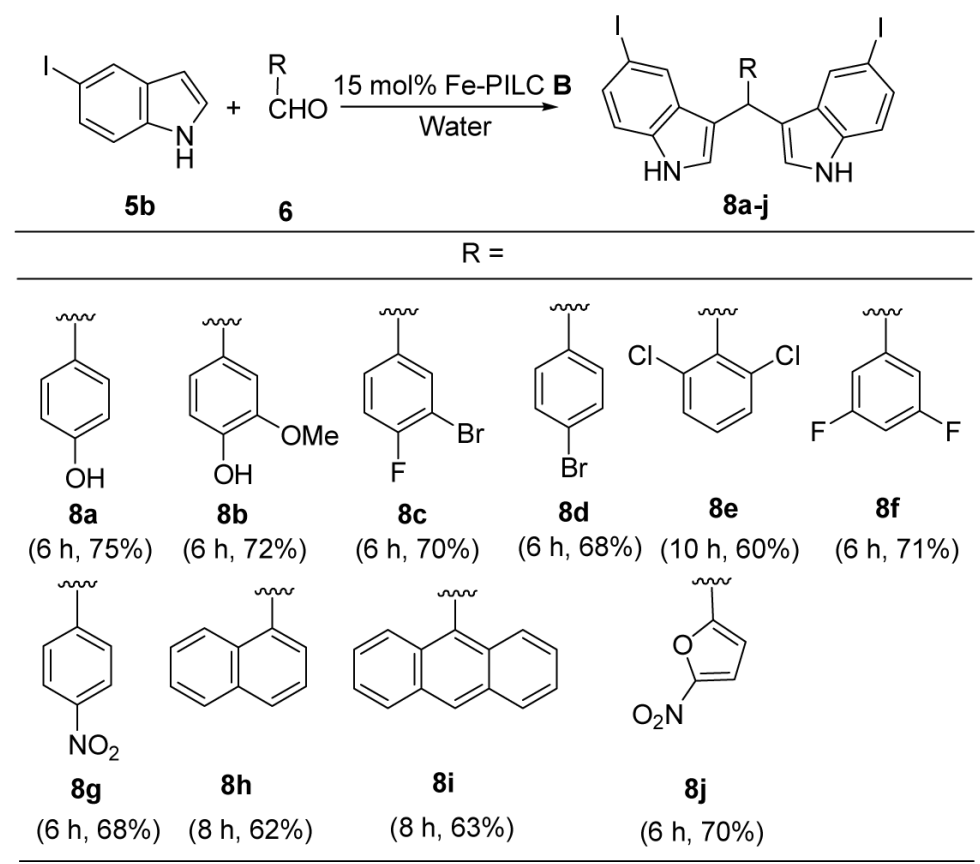

Figure 4.

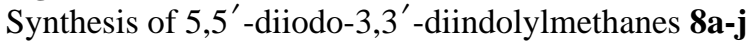




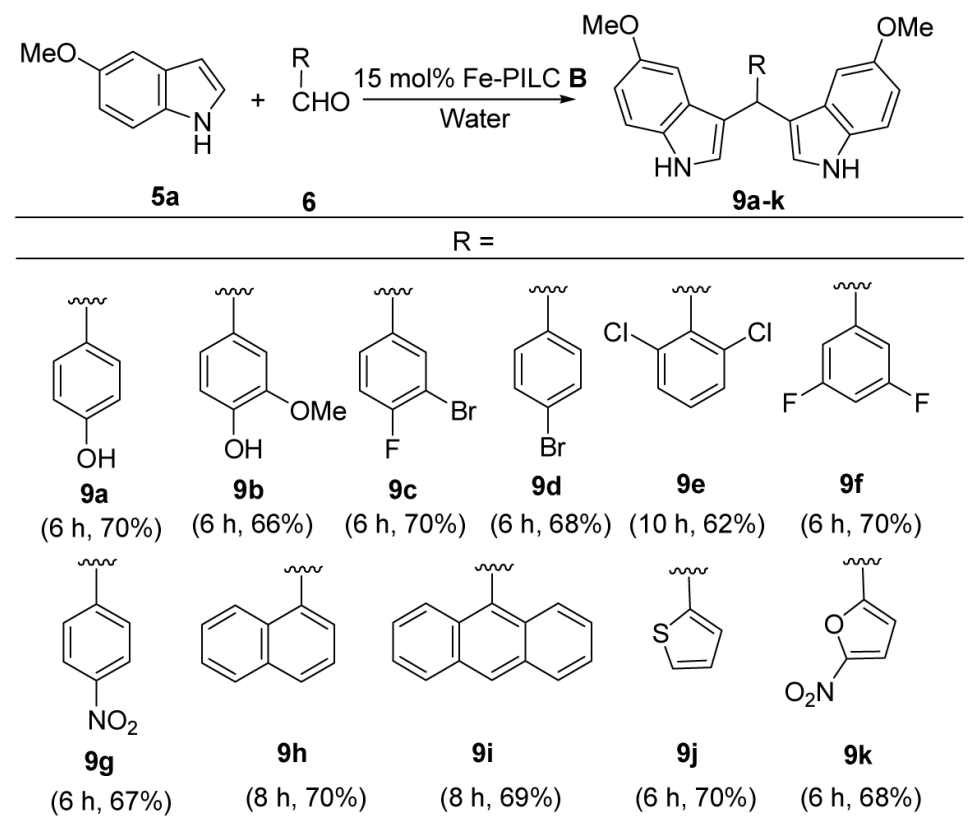

Figure 5.

Synthesis of $5,5^{\prime}$-dimethoxy-3, $3^{\prime}$-diindolylmethanes $\mathbf{9 a - k}$ 

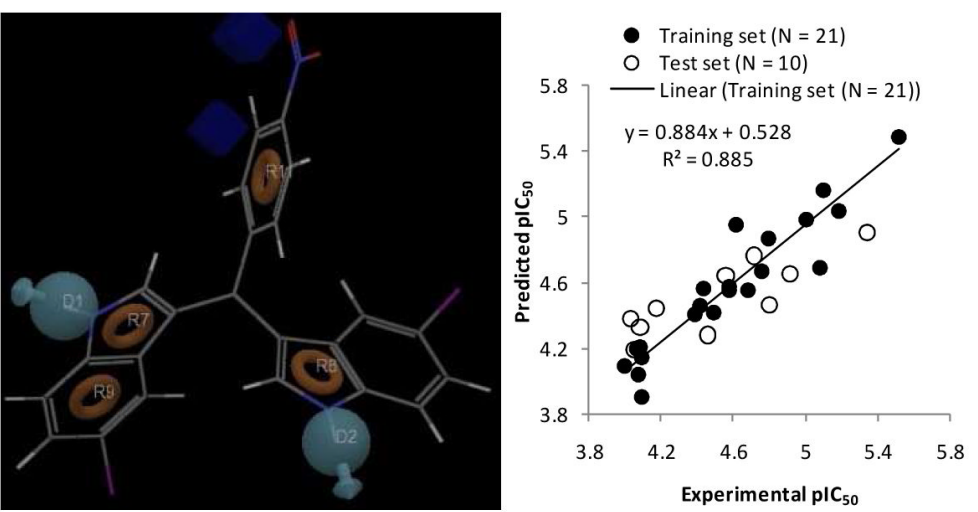

(a)

(b)

Figure 6.

Pharmacophore model for antileishmanial 3,3'-diindolylmethanes. (a) the best phase hypothesis DDRRRR.116 superimposed on one of the most active compound $\mathbf{8 g}$. In the figure a, 'D' denotes H-bond donor and 'R' denotes aromatic ring. (b) Correlation graph between experimental and PHASE predicted antileishmanial activity (\# of PLS factors = 3; $\mathrm{r}^{2}=0.885 ; \mathrm{SD}=0.158 ; \mathrm{F}=43.8 ; \mathrm{p}=3.3 \times 10^{-8} ;$ stability $=0.529 ; \mathrm{RMSE}=0.2658 ; \mathrm{Q}^{2}=$ 0.592; pearson $r=0.836$ ). Training: test $=65: 35$. Test set included $7 \mathbf{a}, \mathbf{7 c}, \mathbf{7 i}, \mathbf{7 m}, \mathbf{8 a}, \mathbf{8 d}$, 9c, $9 \mathrm{~g}, 9 \mathrm{~h}$ and $\mathbf{9 i}$. All remaining analogs were part of training set. 


\section{Table 1}

Optimization of reaction conditions for synthesis of $3,3^{\prime}$-diindolylmethanes

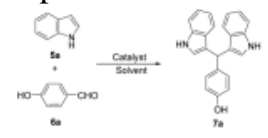

\begin{tabular}{|c|c|c|c|c|c|c|}
\hline Entry & Catalyst $^{a}$ & Mol \% & Solvent & Temp. & Time (h) & Yield $^{b}(\%)$ \\
\hline 1. & Fe-PILC A & 50 & $\mathrm{CH}_{2} \mathrm{Cl}_{2}$ & $\mathrm{rt}$ & 4 & 58 \\
\hline 2. & Fe-PILC A & 50 & Water & $\mathrm{rt}$ & 4 & 54 \\
\hline 3. & Fe-PILC A & 50 & Water & $60^{\circ} \mathrm{C}$ & 6 & 58 \\
\hline 4. & Fe-PILC B & 50 & $\mathrm{CH}_{2} \mathrm{Cl}_{2}$ & $\mathrm{rt}$ & 4 & 75 \\
\hline 5. & Fe-PILC B & 50 & Water & $\mathrm{rt}$ & 4 & 70 \\
\hline 6. & Fe-PILC B & 50 & Water & $60^{\circ} \mathrm{C}$ & 6 & 76 \\
\hline 7. & Fe-PILC B & 30 & Water & $\mathrm{rt}$ & 6 & 76 \\
\hline 8. & Fe-PILC B & 15 & Water & $\mathrm{rt}$ & 6 & 74 \\
\hline 9 & Clay K10 & 50 & Water & $\mathrm{rt}$ & 6 & 0 \\
\hline 10 & Clay K10 & 50 & Water & $\mathrm{rt}$ & 16 & 30 \\
\hline 11. & None & - & $\mathrm{CH}_{2} \mathrm{Cl}_{2}$ & $\mathrm{rt}$ & 10 & 0 \\
\hline 12. & None & - & Water & $\mathrm{rt}$ & 10 & 0 \\
\hline
\end{tabular}

${ }^{a}$ Fe-PILC $\mathbf{A}$ and $\mathbf{B}$ vary in their surface acidity. Fe-PILC $\mathbf{B}$ is more acidic than Fe-PILC $\mathbf{A}$;

$b_{\text {Isolated yield after silica gel column chromatography }}$ 
Table 2

Antileishmanial activity of 3,3' -diindolylmethanes against Leishmania donovani promastigotes and amastigotes

\begin{tabular}{|c|c|c|c|c|c|}
\hline \multirow[t]{2}{*}{ Entry } & \multicolumn{2}{|c|}{ L. donovani $\left(\mathrm{IC}_{50} / \mathrm{IC}_{90}\right)^{a a}$} & \multirow[t]{2}{*}{ Entry } & \multicolumn{2}{|c|}{ L. donovani $\left(\mathrm{IC}_{50} / \mathrm{IC}_{90}\right){ }^{a b}$} \\
\hline & Promastigotes & Amastigotes & & Promastigotes & Amastigotes \\
\hline $7 a$ & 92.84 / 106.4 & $51.33 / 88.88$ & $8 e$ & na / na & na / na \\
\hline $7 \mathbf{b}$ & $85.95 / 98.86$ & $75.00 /$ na & $8 f$ & $24.25 / 41.25$ & $23.18 / 44.49$ \\
\hline $7 c$ & $89.03 / 105.5$ & na / na & $8 g$ & $7.88 / 10.16$ & 8.37 / 38.37 \\
\hline $7 d$ & $84.97 / 95.63$ & $42.17 / 79.46$ & $8 \mathbf{h}$ & na / na & na / na \\
\hline $7 e$ & $82.86 /$ na & na / na & $8 \mathbf{i}$ & na / na & na / na \\
\hline $7 f$ & $41.15 / 75.74$ & $95.86 /$ na & $8 \mathbf{j}$ & $3.02 / 6.22$ & $25.32 / 28.93$ \\
\hline $7 \mathrm{~g}$ & $17.63 / 22.94$ & $47.54 / 74.52$ & $9 \mathbf{a}$ & $81.06 / 90.98$ & $42.89 / 76.31$ \\
\hline $7 h$ & $26.66 / 39.04$ & $41.97 / 76.97$ & $9 b$ & na / na & na / na \\
\hline $7 \mathbf{i}$ & $27.45 / 59.38$ & $35.85 / 75.58$ & $9 c$ & $15.75 / 46.55$ & 47.62 / 66.82 \\
\hline $7 \mathbf{j}$ & $80.72 / 90.79$ & $48.41 / 81.54$ & 9d & $32.70 / 58.46$ & na / na \\
\hline $7 \mathbf{k}$ & $8.35 / 19.78$ & $67.40 / 95.61$ & $9 e$ & na / na & na / na \\
\hline 71 & $15.94 / 54.33$ & $40.79 / 72.26$ & 9f & $26.79 / 65.31$ & $49.64 / 78.71$ \\
\hline $7 \mathrm{~m}$ & $82.04 / 91.90$ & 53.44 / na & $9 \mathrm{~g}$ & $12.08 / 18.81$ & $14.73 / 64.22$ \\
\hline $7 n$ & $100.4 /$ na & $70.21 / 101.28$ & $9 h$ & $66.55 / 82.85$ & $33.19 / \mathrm{na}$ \\
\hline 70 & $6.61 / 12.18$ & $31.54 / 41.82$ & $9 \mathrm{i}$ & $34.65 / 64.92$ & 39.83 / na \\
\hline $8 \mathbf{a}$ & $19.07 / 53.20$ & $39.76 / 52.46$ & $9 \mathbf{j}$ & $38.07 / 65.85$ & $59.02 / 84.82$ \\
\hline $\mathbf{8 b}$ & $20.77 / 37.94$ & $31.58 / 47.24$ & $9 \mathbf{k}$ & $37.27 / 59.98$ & na / na \\
\hline $8 c$ & $9.84 / 18.22$ & $18.25 / 31.43$ & Pentamidine & $3.29 / 6.21$ & $2.9 / 14.3$ \\
\hline $8 d$ & $4.49 / 8.47$ & $13.14 / 46.58$ & Amphotericin B & $0.17 / 0.35$ & $0.13 / 0.37$ \\
\hline
\end{tabular}

na, not active;

${ }^{a}$ Values are in $\mu \mathrm{M}$.

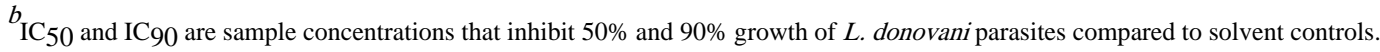


Table 3

Antibacterial activity of 3,3' -diindolylmethanes

\begin{tabular}{|c|c|c|c|}
\hline \multirow[b]{2}{*}{ Entry } & \multicolumn{3}{|l|}{$\mathrm{IC}_{50} / \mathrm{MIC} / \mathrm{MBC}^{a}$} \\
\hline & S. aureus & MRS & M. intracellulare \\
\hline $7 \mathbf{a}$ & 10.47 / 29.59/ na & $17.81 / 59.2 / \mathrm{na}$ & na / na / na \\
\hline $7 \mathrm{c}$ & $9.06 / \mathrm{na} / \mathrm{na}$ & na / na / na & na / na / na \\
\hline $7 d$ & $7.47 / 13.59$ / na & $12.3 / 27.2 / \mathrm{na}$ & $\mathrm{na} / \mathrm{na} / \mathrm{na}$ \\
\hline $7 e$ & 7.84 / na / na & $31.5 / \mathrm{na} / \mathrm{na}$ & $\mathrm{na} / \mathrm{na} / \mathrm{na}$ \\
\hline $7 f$ & $17.19 / 59.2 / \mathrm{na}$ & $36.2 / \mathrm{na} / \mathrm{na}$ & $\mathrm{na} / \mathrm{na} / \mathrm{na}$ \\
\hline $7 \mathrm{~g}$ & $3.76 / 5.98 / \mathrm{na}$ & $9.23 / 23.9 / \mathrm{na}$ & na / na / na \\
\hline $7 \mathrm{~h}$ & $3.79 / 7.02 / \mathrm{na}$ & $6.12 / 14.0 / 56.2$ & na / na / na \\
\hline $7 \mathbf{i}$ & $3.75 / 12.5 / \mathrm{na}$ & $6.30 / 12.5 / \mathrm{na}$ & na / na / na \\
\hline $7 \mathbf{j}$ & $2.36 / 6.41 / 51.3$ & $\mathrm{na} / \mathrm{na} / \mathrm{na}$ & $\mathrm{na} / \mathrm{na} / \mathrm{na}$ \\
\hline $7 \mathrm{k}$ & $2.32 / 3.49 / \mathrm{na}$ & 2.93 / 6.98 / na & $\mathrm{na} / \mathrm{na} / \mathrm{na}$ \\
\hline $7 n$ & $9.15 / 15.2 / \mathrm{na}$ & $13.45 / \mathrm{na} / \mathrm{na}$ & na / na / na \\
\hline 70 & $12.0 / 28.0 / 28.0$ & $8.54 / 14.0 / \mathrm{na}$ & $52.9 / \mathrm{na} / \mathrm{na}$ \\
\hline $8 \mathbf{a}$ & $2.10 / 4.24 / 33.9$ & $1.15 / 2.12 / 10$ & $\mathrm{na} / \mathrm{na} / \mathrm{na}$ \\
\hline $8 b$ & $1.89 / 4.03 / \mathrm{na}$ & $2.11 / 4.03 / \mathrm{na}$ & na / na / na \\
\hline $8 j$ & $7.52 / 16.4 / 16.4$ & $11.28 / 32.8 / \mathrm{na}$ & na / na / na \\
\hline $9 \mathrm{c}$ & $3.45 / 10.5 / \mathrm{na}$ & 4.67 / na / na & $39.6 / 41.8 / \mathrm{na}$ \\
\hline $9 e$ & $7.51 / \mathrm{na} / \mathrm{na}$ & $17.16 / \mathrm{na} / \mathrm{na}$ & na / na / na \\
\hline 9f & $4.05 / 11.71 / \mathrm{na}$ & $6.89 / 11.7 / \mathrm{na}$ & $\mathrm{na} / \mathrm{na} / \mathrm{na}$ \\
\hline $9 \mathrm{~h}$ & $39.7 / \mathrm{na} / \mathrm{na}$ & $\mathrm{na} / \mathrm{na} / \mathrm{na}$ & $\mathrm{na} / \mathrm{na} / \mathrm{na}$ \\
\hline Ciprofloxacin & $0.39 / 1.51 / 1.51$ & $0.39 / 1.51 / 1.51$ & $1.0 / 1.51 / 3.02$ \\
\hline
\end{tabular}

${ }^{a}$ Values are in $\mu \mathrm{M}$. 


\section{Table 4}

Antifungal activity of 3,3'-diindolylmethanes against $C$. neoformans

\begin{tabular}{|c|c|c|c|}
\hline Entry & $\mathrm{IC}_{50} a$ & $\operatorname{MIC}^{a}$ & $\operatorname{MFC}^{a}$ \\
\hline $7 a$ & 18.91 & 29.59 & 59.17 \\
\hline $7 c$ & 35.45 & na & na \\
\hline $7 d$ & 16.88 & 27.17 & 27.17 \\
\hline $7 f$ & 14.64 & 59.17 & na \\
\hline $7 \mathrm{~g}$ & 1.94 & 2.99 & 5.98 \\
\hline $7 h$ & 5.56 & 14.04 & 14.04 \\
\hline $7 \mathbf{i}$ & 5.33 & 12.50 & 12.50 \\
\hline $7 \mathbf{k}$ & 2.32 & 3.49 & 3.49 \\
\hline $7 n$ & 18.93 & 30.49 & 30.49 \\
\hline 70 & 29.64 & na & na \\
\hline $8 \mathbf{a}$ & 1.80 & 4.24 & 4.24 \\
\hline $8 b$ & 3.92 & 32.26 & na \\
\hline $8 c$ & 16.78 & 29.85 & 29.85 \\
\hline $8 d$ & 5.58 & 30.67 & 30.67 \\
\hline 9f & 18.35 & 47.85 & na \\
\hline Amphotericin B & 0.85 & 1.35 & 1.35 \\
\hline
\end{tabular}

